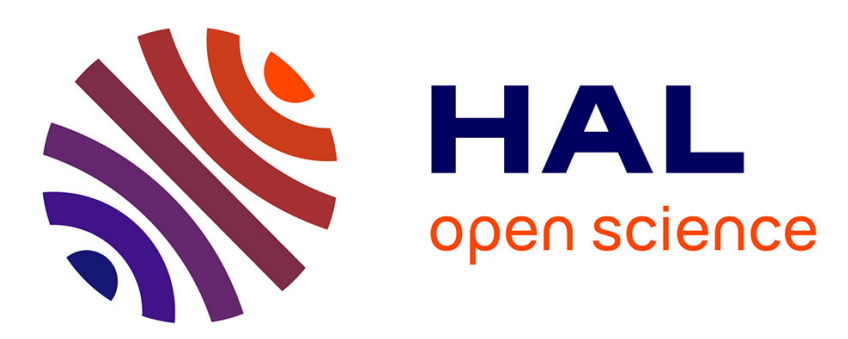

\title{
Le sacrifice du chien dans les communautés grecques, étrusques, italiques et romaines : approche comparatiste Jean-Claude Lacam
}

\section{To cite this version:}

Jean-Claude Lacam. Le sacrifice du chien dans les communautés grecques, étrusques, italiques et romaines : approche comparatiste. Mélanges de l'Ecole française de Rome - Antiquité, 2008, Antiquité, 120 (1), pp.29-80. hal-03519743

\section{HAL Id: hal-03519743 \\ https://hal.science/hal-03519743}

Submitted on 10 Jan 2022

HAL is a multi-disciplinary open access archive for the deposit and dissemination of scientific research documents, whether they are published or not. The documents may come from teaching and research institutions in France or abroad, or from public or private research centers.
L'archive ouverte pluridisciplinaire HAL, est destinée au dépôt et à la diffusion de documents scientifiques de niveau recherche, publiés ou non, émanant des établissements d'enseignement et de recherche français ou étrangers, des laboratoires publics ou privés. 
J.-Cl. Lacam, Le sacrifice du chien dans les communautés grecques, étrusques, italiques et romaines : approche comparatiste, dans MEFRA, 120-1, 2008, p. 29-80.

Résumé

Mentionnée par des sources aussi rares que disparates, souvent perçue de surcroît comme une incongruité, l'utilisation des chiens à des fins rituelles reste mal connue. Pourtant, la diffusion des sacrifices canins dans le monde antique s'avère fort étendue tant dans le temps que dans l'espace (de Didymes à Athènes, de Gubbio à Rome,...). Moins fréquente il est vrai que celle d'ovins ou de bovins en raison du statut domestique privilégié de la victime, l'offrande d'un chien ne relève pourtant pas de manipulations magiques : elle obéit à un strict ritualisme, propre à chaque communauté. Les divergences de pratiques ne sauraient masquer de frappantes homologies : partout, le sacrifice canin honore, en un lieu de passage, une divinité ambivalente qui, comme l'animal démembré à son intention, veille sur les seuils, de la vie et de la mort, de la civilisation et de la barbarie 
Sur une coupe attique de Cerveteri ${ }^{1}$ (fig. 1), une peinture représente une facétie d'Hermès qui accompagne au sacrifice une victime étrange : sous le travestissement d'un cochon, c'est en réalité un chien qu'il conduit. L'utilisation des chiens à des fins rituelles a été bien souvent perçue par les auteurs anciens ${ }^{2}$ et plus encore par les commentateurs actuels ${ }^{3}$ comme une incongruité ${ }^{4}$. Une approche comparatiste, enrichie de récentes données archéologiques ${ }^{5}$, devrait permettre d'apporter quelques éclaircissements à des rites qui demeurent pour nous souvent bien obscurs ${ }^{6}$.

Les études sur «la place du chien dans l'économie religieuse ${ }^{7}$, depuis la dissertation de H. Scholz ${ }^{8}$, se sont intéressées davantage au lien de certaines divinités avec les chiens ${ }^{9}$ qu'à l'insertion de cet animal dans les rites et davantage encore à l'étiologie des rituels canins qu'à leur description, faisant la part belle à la magie ${ }^{10}$.

${ }^{1}$ Conservée au Kunsthistorisches Museum de Vienne, cf. R. Bianchi Bandinelli, 1961, p. 5 fig. 6.

${ }^{2}$ Ovide, Fastes VI, 158-159; Plutarque, Romulus 21.

${ }^{3}$ Ils témoignent, au mieux, d'une indifférence polie : G. Dumézil, 1987 en souligne la rareté, sans chercher à l'expliquer.

${ }^{4}$ Qui ne peut provenir, selon ces auteurs - antiques et modernes, que de peuples étrangers. Ainsi Columelle, De l'Agriculture X, 342-343, selon qui le sacrifice canin aurait été enseigné aux Romains par les Etrusques. Ainsi, pour l'époque actuelle D. Soren, 1998, p. 622 (à propos des sacrifices canins des Macédoniens) : «This custom was probably derived from Hittite or even earlier rituals and was passed on the Romans ». Ainsi J. Bremmer, 1994, p. 41 à propos des rituels canins pratiqués à Sardes : « excavations have demonstrated the sacrifice of dogs to Apollo in Didyma, but this is probably due to influence from Asia Minor: Hittites and Lydians happily consumed dog meat ». Ainsi R. Schilling, 1993, p. 124 n. 79 voit dans le sacrifice du chien aux Lupercales une « hellénisation subreptice »!

${ }^{5}$ Qui ont pu bénéficier d'enquêtes archéozoologiques plus systématiques, même si l'on peut regretter l'utilisation encore restreinte de cette science dans l'étude des rituels antiques, cf. J. De Grossi Mazzorin, 2001, p. 79 : « non sono multi i santuari in Italia indagati da un punto di vista archeozoologico $»$.

6 Je voudrais ici remercier vivement John Scheid, Dominique Briquel, Olivier de Cazanove et Patrice Méniel de m'avoir aidé, en relisant cet article, à lever quelques ombres.

${ }^{7}$ M. Nouilhan, J.- M. Pailler, P. Payen, 1999, p. 234.

${ }^{8}$ H. Scholz, 1937.

${ }^{9}$ Cf. H. Scholz, 1937 ; N. J. Zagarianis, 1980-1981.

${ }^{10}$ Le titre exact - et significatif - de la dissertation de H. Scholz est d'ailleurs : Der Hund in der griechisch-römischen Magie und Religio. Les études sur les Robigalia ont ainsi souvent été menées sous l'angle de la magie : W. Warde Fowler, 1925, p. 90 évoque «a piece of sympathetic magic » (expression que reprend H. Scullard, 1981 109, à propos de l'augurium canarium) ; N. Turchi, 1939 parle de « magia imitativa »; K. Latte, 1960, p. 67-68 ; J. Bayet, 1971, p. 98 explique : « ils conjurent, magiquement encore, Robigo »; F. Blaive, 1995, p. 282 se défend même de prendre quelque distance à l'égard de ce type d'approche: " en nous gardant bien de dénier tout caractère magique " [à ce rite des Robigalia]. A propos des sacrifices canins attestés au cimetière 
Plus que leur origine et leur signification profonde, qui ont souvent suscité de longs développements et accaparé la réflexion, cette recherche entend examiner les rites euxmêmes, d'autant que l'interprétation de ces actes religieux pose de redoutables et inextricables problèmes, comme le reconnaît Plutarque à propos des Lupercales : « quant aux rites auxquels ils se livrent, il est difficile d'en comprendre les raisons ${ }^{11}$. Il est vrai, de plus, que l'exégèse religieuse pratiquée par les Anciens - Ovide en tête participait plus du jeu que d'une intention de vérité ${ }^{12}:$ le discours sur le rite ne faisait pas partie de la religion ${ }^{13}$. Comme l'a démontré J. Scheid, « la seule chose qui compte, c'est faire $"{ }^{14}$. Aussi, il s'agira de cerner les gestes et les paroles, les offrandes et les acteurs de ces rituels canins.

La perspective comparatiste a souvent été aussi ignorée ou appliquée de manière trop restrictive. De nombreux commentateurs ont analysé individuellement ces $\operatorname{rites}^{15}$; d'autres ont comparé entre eux les rituels grecs ${ }^{16}$ ou bien les romains, rapprochant par exemple l'augurium canarium des Robigalia ${ }^{17}$; d'autres à l'inverse ont élargi à l'excès la perspective en mettant en regard les rituels macédoniens et les pratiques hittites ${ }^{18}$, voire même les sacrifices du monde romain avec les pratiques des disciples de Zoroastre dans l'ancienne Perse à l'Age du bronze, et... les cérémonies funéraires accomplies à Ashdod (au sud d'Israël) ${ }^{19}$. Mais aucun n'a mis en parallèle les rituels canins des Grecs avec ceux des Étrusques, des Italiques et des Romains - autant de peuples pourtant en contact régulier et qui partagent bon nombre de traits culturels ${ }^{20}$. Le témoignage, central sur ce sujet, des Tables Eugubines a été à cet égard quasi systématiquement laissé de côté $^{21}$, même dans les analyses récentes ${ }^{22}$, sans doute en raison de l'obscurité persistante

infantile de Poggio Gramignano, M. MacKinnon, 1998, p. 549-550 parle de «magie noire » et de sorcellerie ». Pour reprendre une formule ironique de G. Dumézil qui concernait d'autres pratiques, nous serions tentés, à la lecture des commentaires modernes, de croire que le monde du sacrifice canin, c'est "magic city »! Il est vrai que tous les ingrédients pour une approche magique semblent réunis: les rites se déroulent souvent la nuit, parfois à la pleine lune, en l'honneur de divinités chthoniennes, dans un cadre souvent funéraire, autour d'une victime insolite.

${ }^{11}$ Plutarque, Romulus 21, 6

12 J. Scheid, 1992.

13 «Exegesis was not a necessity », J. Scheid, 1992, p. 122.

${ }^{14}$ J. Scheid dans un entretien à www.parution.com. Cf. aussi J. Scheid, 2005.

${ }^{15}$ Par exemple L. Delatte, 1937 (augurium canarium).

${ }^{16}$ Cf. C. Mainoldi, 1984.

${ }^{17}$ Cf. J. Bayet, 1926, p. 96 ; D. Porte, 1985, p. 152, 156-159 ; J.-N. Robert, 1985, p. 301-303 ; H. Scullard, 1981, p. 108-109.

${ }^{18}$ Cf. O. Masson, 1950.

${ }^{19}$ Cf. D. Soren, 1998, p. 620-621.

${ }^{20}$ Fournissant ainsi un « cadre cohérent » (R. Robert, 1993, p. 124) à la comparaison.

${ }^{21}$ Exceptés les éditeurs de ces Tables, qui se sont toutefois bien souvent contentés de citer les textes latins mentionnant les sacrifices de chien(s), cf. J. W. Poultney, 1959, p. 176-177. Quelques rares commentateurs s'y sont référés, en faisant preuve parfois d'une certaine méconnaissance des réalités rituelles eugubines : cf. R. Robert, 1993, p. 123 n. 15 qui évoque la divinité Hontia (sic). Une exception : A. L. Prosdocimi, 1978, p. 760-761 qui s'intéresse au rituel ombrien mais pour le comparer (et l'assimiler) au seul augurium canarium.

${ }^{22}$ F. Blaive, 1995. 
du texte ombrien ${ }^{23}$. A cette vision trop souvent faussée, nombre d'études ont ajouté un comparatisme dévoyé, avide d'analogies, pratiquant des rapprochements hâtifs, voire même des assimilations abusives ${ }^{24}$, dans le but tacite ou avoué de retrouver un archétype - indo-européen, le plus souvent ${ }^{25}$. Pourtant, une analyse comparatiste digne de ce nom ne doit pas s'assigner pour but un relevé exclusif des ressemblances, elle doit s'attarder au contraire sur les différences dont elle cherche à dresser un scrupuleux « inventaire ${ }^{26}$ afin de saisir, avec une totale absence de parti pris, la spécificité de chaque système religieux. Dans cette confrontation des rituels canins, il faudra ainsi déterminer s'il s'agit de rites uniformément pratiqués, réguliers ou extraordinaires, s'ils mettent en œuvre un vocabulaire, des intervenants et des gestes particuliers, s'ils s'adressent à des divinités propres.

Les sources concernant ces rituels sont peu nombreuses et surtout très diverses dans leur nature - uniquement épigraphiques pour l'Ombrie et archéologiques pour les autres régions italiques, archéologiques et littéraires pour le monde romain, la Grèce et l'Etrurie -, dans leurs dates - depuis l'époque « archaïque » pour certains témoignages archéologiques jusqu'à l'époque impériale pour les textes historiques -, mais aussi dans leurs perspectives : alors que les Tables Eugubines offrent une description «brute » de rituels canins, sans exégèse, Ovide comme Plutarque commentent, jugent et tentent d'interpréter plus ou moins scientifiquement ${ }^{27}$ ces rites; souvent aussi, les auteurs

23 Même si les linguistes s'accordent sur une traduction globale, de nombreuses obscurités persistent, comme l'a souligné le principal éditeur de cette inscription J. W. Poultney, 1959, p. 14 en évoquant les « unsolved problems in the interpretation of the Iguvine Tables ». Ce qu'ont confirmé plus récemment C. Malone, S. Stoddard, 1994, p. 158 et J. Scheid, $1997^{2}$, p. 53.

${ }^{24}$ Par exemple A. L. Prosdocimi, 1978, p. 760-761 qui assimile 1'Huntia et l'augurium canarium.

${ }^{25}$ Cf. F. Blaive, 1995, p. 289 : « nous pensons - en ce qui concerne le sacrifice du chien - que la solution indo-européenne s'est révélée la plus fructueuse pour résoudre, sinon la totalité, du moins la plus grande partie de l'énigme posée par les Robigalia». A. L. Prosdocimi, 1978, p. 761 : «Il KATLE TICEL richiama l'augurium canarium romano : indizi antiquari di più ordini provano l'affinità, per certi aspetti, forse, la matrice comune della situazione calendariale e dello stesso modo di esprimerla (con un rimando ad un archetipo-brogliaccio del rituale) »».

${ }^{26}$ Pour reprendre le titre de P. Veyne, 1976.

${ }^{27}$ Ce qui a valu à Ovide d'être pendant longtemps méprisé par les historiens de la religion (G. Wissowa, 1904, p. 129-143 ; G. Dumézil, 1966 71) avant d'être réhabilité par R. Schilling, 1979; D. Porte, 1985. J. Scheid, 1992, p. 123 a éclairci la démarche d'Ovide en la replaçant dans les pratiques exégétiques courantes des Romains en matière de religion: "Ovid's methods in his Fasti are the traditional methods of exegesis, with all their exuberance. They are the sames as Varro's, Verrius Flaccus' or Plutarch's. The only difference between these authors is the literary or scientific style of their essays. [...] Ovid writes his Fasti following the model of Callimachean poetry, allowing him to mix Roman and Greek references. None of these choices make their products inferior or superior to other commentaries ; they are simply literary choices. [...] From this perspective we no longer need to accuse Ovid of incoherence, incompleteness, let alone incompetence in religious matters. From the exegetical standpoint it is nonsense to blame Ovid for modifying his interpretation from one passage to another. Those were the laws of the game of exegesis [...] There was no necessity for an unique and unified sense. In fact the best that Roman society could 
anciens ont un regard d'observateurs extérieurs, d' " ethnologues " friands de détails surprenants. Ainsi Tite-Live semble fasciné par les rituels macédoniens ${ }^{28}$, Pausanias curieux des pratiques des Colophoniens et des Spartiates ${ }^{29}$, Plutarque perplexe devant les rites des Luperques $^{30}$ : une telle prédilection pour l'insolite reflète-t-elle fidèlement la place effective des rituels canins dans ces sociétés ? Même les sources plus directes épigraphiques et archéologiques - apparaissent, elles aussi, difficilement représentatives : ainsi la place éminente accordée au sacrifice canin dans les Tables Eugubines est-elle le propre de toutes les communautés ombriennes ou plus vraisemblablement d'une seule confraternité bien précise? En raison d'une documentation aussi partielle et partiale, les généralisations sont délicates.

1. Des sacrifices canins amplement diffusés ...

L'inventaire des attestations de sacrifices canins (tableau 1) révèle une diffusion étendue de ces rites dans l'espace (fig. 2,3) et dans le temps.

\section{1. En terre grecque}

En terre hellénique, le sacrifice du chien est attesté par quatre auteurs grecs (Aristophane, Plutarque, Pausanias et Lycophron) et trois écrivains romains (Tite-Live, Quinte-Curce et Ovide), qui composent tous - hormis Aristophane - à l'époque impériale (aux Ier et IIè s.).

A lire Plutarque, dans ses Questions Romaines, «à peu près tous les Grecs » le pratiquent $^{31}$, ce qu'il confirme dans Romulus : « les Grecs [...], dans les cérémonies de purification, apportent des petits chiens et réalisent en maint endroit ce que l'on appelle periskylakisme $\gg{ }^{32}$. Les habitants de Sparte, plus particulièrement, y ont recours pour honorer Ényalios ${ }^{33}$, tout comme les Béotiens ${ }^{34}$ et plus encore les Macédoniens dans leurs rituels guerriers ${ }^{35}$. Ce type de sacrifice est aussi attesté chez les habitants de

expect from a scholar or a poet was his capability of producing the greatest number of interpretations $\gg$.

28 Tite-Live XL, 6, 1-3.

${ }^{29}$ Pausanias III, 14, 9.

${ }^{30}$ Plutarque, Questions Romaines 68, 111 ; Romulus 21, 4-9. Cf. B. Liou-Gille, 1980, p. 188: «Plutarque parle abondamment de cette fête étrange, qui semble l'avoir fasciné : il est le seul à la décrire avec précision [...]; il est possible que Plutarque ait été un témoin visuel de la cérémonie »; p. 190 : «Quant au sacrifice du chien, il serait déraisonnable de le mettre en doute. Plutarque y revient avec une insistance particulière ».

${ }^{31}$ Plutarque, Questions Romaines 68.

${ }^{32}$ Plutarque, Romulus 21.

${ }^{33}$ Plutarque, Questions Romaines 111 ; Pausanias, III, 14, 9.

${ }^{34}$ Plutarque, Questions Romaines 111.

35 Tite-Live, XL 6, 1-3 ; Quinte-Curce, X 9, 12. 
Samothrace $^{36}$, les Thraces ${ }^{37}$, les Argiens ${ }^{38}$ et les Colophoniens ${ }^{39}$, plus modestement chez les Éléens ${ }^{40}$ et même en Attique si l'on considère que l'action décrite par le dramaturge athénien ${ }^{41} \mathrm{~s}$ 'y déroule et si l'on interprète comme un acte sacrificiel la scène représentée sur un lécythe d'Athènes (fig. 4) : une femme tient d'une main un chien par la queue à proximité de trois torches - sans doute celles d'Hécate - et de l'autre un panier d'offrandes sacrificielles ${ }^{42}$. D'ailleurs au coeur d'Athènes, sur l'agora, dans un puits situé au nord-ouest de l'Héphaïstéion, ont été mis au jour en 1939 les os de quatre-vingt cinq chiens ${ }^{43}$ qui accompagnaient les restes de cent-soixante-quinze nouveau-nés (sans doute victimes d'une épidémie ${ }^{44}$ ) ainsi qu'une épée et un pilier hermaïque ${ }^{45}$ pourvu d'une tête de femme : la divinité liée à ce rite mystérieux ${ }^{46}$ semble être Aphrodite $^{47}$, si l'on suit Pausanias ${ }^{48}$ qui indique que tout près du temple d'Héphaïstos se trouvait celui d'Aphrodite Ourania.

Quelques témoignages archéologiques permettent d'élargir encore la carte du sacrifice canin aux rives d'Asie mineure, à Didymes (à proximité de Milet) où des fouilles ont révélé l'immolation de chiens en l'honneur d'Apollon ${ }^{49}$ et en Lydie à Sardes où ont été mis au jour des ossements de jeunes chiens (datables du VIe s. av. J.-C. ${ }^{50}$ ),

${ }^{36}$ Lycophron, Alexandra 75-78 : « Je pleure sur toi [...] fils de 1'Atlantide qui [...] se sauva à la nage comme la mouette de Rhithymne, ayant quitté l'antre de Zérinthe où l'on immole des chiens à une déesse ».

37 Ovide, Fastes I 309-310 : «J'ai vu que les Sapéens et les habitants de tes pentes neigeuses, ô Hémus, offrent à Trivia des entrailles de chien ».

${ }^{38}$ Plutarque, Questions Romaines 52 .

${ }^{39}$ Pausanias, III, 14, 9.

${ }^{40}$ Pausanias, VI, 2, 4-5.

${ }^{41}$ Aristophane, fr. 204.

${ }^{42}$ Cf. L. Deubner, 1960, p. 2, H. Scholz, 1937, p. 43. Il s'agit probablement d'une illustration des Hékatès deipna (cf. C. Mainoldi, 1984, p. 56).

43 T. L. Shear, 1939, p. 238-239 ; J.-L. Angel, 1945, p. 311-312 : E. B. Harrison, 1965, p. 167-169 ; LIMC, II, 630 ; V. Pirenne-Delforge, 1994, p. 19-20. Le contenu de ce puits a été daté du IIe s. av. J.-C.

44 J.-L. Angel, 1945, p. 312.

${ }^{45}$ Ont aussi été retrouvés les ossements d'un adulte, d'un enfant d'environ 11 ans et de quelques autres animaux domestiques, cf. E. B. Harrison, 1965, p. 168.

${ }^{46}$ V. Pirenne-Delforge, 1994, p. 19 parle de « curieuse trouvaille ».

${ }^{47}$ E. B. Harrison, 1965, p. 167-169 ; LIMC, II, 630 préfèrent y voir Artémis.

${ }^{48}$ Pausanias, I, 14, 7. Il explique aussi qu' "Égée institua ce culte à Athènes parce qu'il pensait que s'il n'avait pas d'enfant - il n'en avait pas encore à l'époque - et si le malheur s'était abattu sur ses sœurs, c'était à cause de la vengeance de la déesse Ourania ». Il existe à l'évidence un lien entre la déesse et la fécondité. Les (rares) commentateurs de cette découverte y ont vu un aspect propitiatoire ou apotropaïque (LIMC, II, 630 ; V. Pirenne-Delforge, 1994, p. 20).

${ }^{49}$ Cf. J. Bremmer, 1994, p. 41. La présence d'ossements animaux dans un sanctuaire ne signifie pas systématiquement l'existence de pratiques sacrificielles (il faut tenir compte $\mathrm{du}$ contexte stratigraphique, de l'association ou non de ces os avec ceux d'autres animaux, avec du matériel en céramique, ...). Sur les apports pour les rites de ce type de matériel archéologique et les manières de l'utiliser, cf. P. Méniel, 1992; W. Van Andringa, S. Lepetz, 2003 ; S. Lepetz, W. Van Andringa, 2004 ; M. Osanna, 2004, p. 53.

${ }^{50}$ Cf. L. P. Day, 1984, p. 25. 
accompagnés de vaisselle en céramique ${ }^{51}$ et d'un couteau, dans des cruches enfouies ${ }^{52}$, ainsi qu'à la Grande Grèce, à Centocamere près de Locres, dans le sanctuaire d'Aphrodite (fig. 5$)^{53}$ qui a révélé dans les trois cent soixante-et-onze bothroi - creusés entre 550 et 350 av. J.-C. - des restes sacrificiels de chiens mêlés à ceux d'autres animaux (cochon, brebis, bœuf) ${ }^{54}$.

Une telle pratique n'est donc pas le propre d'une cité ou d'une communauté précise : une si ample diffusion (fig. 2) prouve son ancrage et sa relative fréquence dans le ritualisme grec.

\section{2. Sur le sol étrusque et italique}

Pour l'Etrurie, une seule source littéraire, très réduite, nous renseigne : Columelle soutient que le sacrifice du chien pratiqué par les paysans romains «pour calmer la fureur des vents et détourner les intempéries, [...] pour empêcher la malfaisante Robigo de brûler les plantes quand elles sont vertes " leur a été enseigné par les Toscans ${ }^{55}$. L'archéologie vient combler pour une petite part ces lacunes. A Ortaglia, des restes de chiens et de loups ont été retrouvés dans le puits du sanctuaire ${ }^{56}$, ainsi que le squelette complet d'un chien adulte dans celui de Pyrgi, devant le temple A, à côté des restes d'un loup et d'une brebis ${ }^{57}$. Des ossements d'au moins un chien ont aussi été mis au jour dans le sanctuaire de San Giovenale ${ }^{58}$, ainsi qu'à Fiorano Modenese ${ }^{59}$ où ils présentent des lésions occasionnées par un couteau (sacrificiel ?), tout comme à Casale di Rivalta où l'on a retrouvé en outre une petite lame de bronze dans laquelle certains ont vu un instrument cultuel ${ }^{60}$. Dans le complexe de Tarquinia, ont été dégagés les ossements de sept chiens dont l'un était enterré avec des bronzes et des os de bovins, d'ovins et de porcins ${ }^{61}$. A Cortona, ce sont deux statuettes de $\operatorname{chien}^{62}$ en bronze qui ont été découvertes, chacune portant l'inscription d'un théonyme ${ }^{63}$ : s.calustla sur l'une

${ }^{51}$ Un pot à anse (chytra), un skyphos, une oenochoe, un plat.

${ }^{52}$ Cf. C. H. Greenewalt Jr, 1978 ; C. Mainoldi, 1984, p. 57.

${ }^{53}$ Qui n'était peut-être pas la bénéficiaire de ce sacrifice comme l'a révélé une dédicace, retrouvée dans le sanctuaire, à Kybala de la fin du VIIe-début VIe s. av. J.-C., cf. M. Torelli, 599 : " la Cibele asiatica e lidia in particolare, cui tradizionale il sacrificio del cane e che la tradizione ionica arcaica identificava con Afrodite ».

${ }^{54}$ Cf. E. Lissi, 1961, p. 113.

${ }^{55}$ Columelle, De l'Agriculture X, 342-343.

${ }^{56}$ Cf. S. Bruni, 2003.

${ }^{57}$ Cf. L. Caloi, M.-R. Palombo, 1980 qui propose une datation de la fin du IVe s. ou du début du IIIe s. av. J.-C.

${ }^{58}$ C. Sorrentino, 1981.

${ }^{59}$ A. Gianferrari, 1995, p. 132.

${ }^{60}$ Cf. R. Farello, 1990 ; A. Gianferrari, 1995, p. 134 ; C. de Simone, 1997, p. 199 ;

R. Macellari, 1990.

${ }^{61}$ C. Chiaromonte Treré, 1988.

62 Il s'agit bien à l'évidence d'un chien, sur l'exemplaire qui a été conservé. Les doutes de P. Defosse, 1971, p. 498 (« il n’est guère aisé de décider si l'animal tient davantage du chien ou du loup ») sont surprenants.

${ }^{63}$ M. Pallotino, 1954, p. 642-643. Cf. A. Gianferrari, 1995, p. 134 ; C. de Simone, 1997, p. 199. 
(fig. 6) et tinscvil sur l'autre ${ }^{64}$; et à Castelvenere in Garfagnana, un chien stylisé en bronze $^{65}$ aux côtés d'autres statuettes de femmes ou d'hermaphrodites.

Quant aux rituels canins dans le monde italique, nous n'en saurions presque rien sans les Tables Eugubines ${ }^{66}$ qui réservent au sacrifice du chien (katel ${ }^{67}$ ) une place éminente, nous offrant une description très précise des gestes et des paroles mis en œuvre, des offrandes et des ingrédients présentés. Des ossements canins ont aussi été mis au jour dans quelques sanctuaires osco-ombriens, en Lucanie, particulièrement. Ainsi, récemment, dans le lieu de culte de Torre di Satriano, qui a été édifié au IVe s. av. J.-C., ont été exhumés, au milieu d'os de bovins, d'ovins et de caprins, les restes de chiens dans différents contextes stratigraphiques ${ }^{68}$ ainsi qu'un squelette canin presque complet à proximité d'une canalisation antique ${ }^{69}$. Une situation assez semblable se retrouve à l'heraion du Sele $^{70}$ où a été retrouvé dans un puits fermé par des blocs de grès un matériel votif et rituel datable des IVe-IIIe s. av. J.-C. composé d'éléments en céramique et d'ossements animaux - dont quelques-uns de chien reposaient au fond mais aussi dans la partie supérieure ${ }^{71}$.

\section{3. Dans le monde romain}

Plusieurs découvertes archéologiques permettent d'attester la pratique des sacrifices canins dans le monde romain également. Au coeur même de la Ville, des restes canins ont été mis au jour dans l'aire sacrée de Sant'Omobono ${ }^{72}$ (fig. 7) où l'analyse du matériel ostéologique a montré que les - souvent très jeunes - chiens représentaient, certes loin derrière les bovins, les ovins et les caprins, une modeste part des offrandes sacrificielles. De même, à proximité du Lapis Niger, ont été retrouvés une tête de chien en terre cuite ${ }^{73}$ (fig. 8) et des os canins mélangés à des restes d'autres animaux ${ }^{74}$. Dans

${ }^{64}$ Cet exemplaire qui se trouvait au Musée Coltellini de Cortona a disparu (cf. A. Neppi Modona, 1977, p. 146).

${ }^{65}$ A. Gianferrari, 1995, p. 134 ; P. Mencacci, M. Zecchini, 1976, p. 219.

66 TE IIa 15-44. Les mots osco-ombriens en alphabet indigène sont présentés en caractères gras, distincts en cela des termes en alphabet latin qui figurent en italique. En l'absence d'une connaissance assurée de la grammaire osco-ombrienne et pour éviter une latinisation hors de propos, tous les termes seront cités tels qu'on les rencontre dans les Tables, sans translation qui les rattacherait à un nominatif ou un infinitif nécessairement incertains.

${ }^{67}$ Le terme katel que l'on peut aisément rapprocher du latin catulus a été compris par la plupart des commentateurs comme un chien (cf. A. Ernout, 1961, p. 81 ; A. J. Pfiffig, 1964, p. 64 ; A. L. Prosdocimi, 1978, p. 761 ; A. Ancillotti, R. Cerri, 1996, p. 377 ; J. Untermann, 2000, p. 375-376).

${ }^{68}$ M. Osanna, T. Giammatteo, 2001, p. 109.

${ }^{69}$ M. Osanna, 2004, p. 54.

${ }^{70}$ Le territoire de Poseidonia est resté grec du VIIe au Ve s. av. J.- C. puis est passé (au cours des Ve-IVe s.) sous domination lucanienne jusqu'à la colonisation romaine.

${ }^{71}$ Cf. P. Zancani Montuoro, 1937.

${ }^{72}$ Cf. A. Gianferrari, 1994, p. 135 ; A. Tagliacozzo, 1989, p. 65.

${ }^{73}$ Cf. E. Gjerstad, 1960, p. 249.

${ }^{74}$ Ovins, porcins, bovins et même vautour, cf. G. Boni, 1899, p. 158, 168 ; A.

Gianferrari, 1994, p. 136 ; E. Gjerstad, 1960. 
l'aire du sanctuaire de Vesta ${ }^{75}$, mêlés à des offrandes votives, des ossements d'un jeune chien (mais aussi de bovins, de porcs, d'ovins et d'un cervidé) ont été déterrés. En outre, auprès de la porta Mugonia, au pied du Palatin, un squelette de chien a été découvert $^{76}$, ce qui peut faire songer aux squelettes enfouis, au début du IIIe s. av. J.-C., au pied des murailles des colonies de Paestum ${ }^{77}$ et d'Ariminum ${ }^{78}$.

A Satricum (Borgo Le Ferriere), des os de chiens ${ }^{79}$, mêlés à ceux d'autres animaux (bovins, ovins, porcins) et à des fragments de céramique, ont été exhumés dans le dépôt II, pour lesquels l'analyse stratigraphique garantit qu'ils proviennent de rituels sacrificiels accomplis aux IVe-IIIe s. av. J.-C. ${ }^{80}$ dans le sanctuaire proche (qui est vraisemblablement celui de Mater Matuta ${ }^{81}$ ). Les os de sept chiens ${ }^{82}$ mêlés à ceux d'autres animaux ont aussi été mis au jour à Lavello près de Gravetta ${ }^{83}$, en Lucanie intérieure, dans un petit sanctuaire, apparu au moment de la romanisation ${ }^{84}$, fréquenté entre le IIIe et Ier s. av. J.-C. et dont nous ignorons la divinité titulaire ${ }^{85}$ : les ossements canins sont d'ailleurs les restes sacrificiels les plus représentés dans ce lieu de culte, en quantité égale aux os de chèvres et d'ovins réunis ${ }^{86}$.

A une époque beaucoup plus tardive, vers $450^{87}$, au sud de l'Ombrie romaine et encore polythéiste, près de la ville de Lugnano in Teverina (dans la villa de Poggio Gramignano), des rituels canins ont, semble-t-il, été accomplis dans le cadre de pratiques funéraires ${ }^{88}$ : en effet, des fouilles américaines récentes ont révélé aux côtés

${ }^{75}$ Cf. G. Boni, 1900, p. 173-174 ; A. Gianferrari, 1994, p. 137 ; E. Gjerstad, 1960, p. 310-311, 315 fig. 4.

${ }^{76}$ Cf. A. Carandini, 1997, p. 199.

${ }^{77}$ Sous un « remblai de pierre », cf. R. Robert, 1993, p. 122.

78 Cf. J. Ortalli, 1990 (p. 111 : sans doute un «volpino ») ; G. Giusberti, 1990 ; R. Robert, 1993. A proximité, ont été retrouvés aussi quelques restes osseux d'un bœuf et d'un cochon.

${ }^{79}$ Deux adultes, et un jeune (ou de petite taille).

${ }^{80}$ Cf. W. Prummel, 1996, p. 432, 434, 442.

${ }^{81}$ Cf. W. Prummel, 1996, p. 420.

${ }^{82}$ Dont une majorité est de petite taille et dont les squelettes sont incomplets, cf.

S. Sublimi Saponetti, 1991.

83 Lavello correspond sans doute à la colonie de Forentum, cf. M. Tagliente, M. P. Fresa, A. Bottini, 1991.

${ }^{84}$ Cf. M. Tagliente, M. P. Fresa, A. Bottini, 1991, p. 101 ; cette région est passée sous contrôle des Romains au début du IVe s. av. J.-C. (cf. Tite-Live, IX, 20 ; Diodore de Sicile, XIX, 65, 7).

${ }^{85}$ Selon M. Tagliente, M. P. Fresa, A. Bottini, 1991, p. 103 n. 27, il pourrait s'agir

d'Athena Ilias (présente à Lucera).

${ }^{86}$ Cf. S. Sublimi Saponetti, 1991, p. 108: les os de canis familiaris représentent exactement 27, $59 \%$ des espèces présentes, comme les os d'ouis et de capra réunis, alors que ceux de sus scrofa représentent 13, $79 \%$, de bos 10,34\%, de cervus 10, $34 \%$, d'equus caballus 3, $45 \%$, d'asinus 3,45\%, de testudo 3, $45 \%$.

${ }^{87}$ Cf. D. Soren, T. Fenton, W. Birkby, 1998, p. 486.

88 Il ne s'agit pas de traiter ici de l'enterrement - assez fréquent - dans ces communautés, de chien(s) aux côtés de leur maître (cf. J. De Grossi Mazzorin, 2001, p. 80) : il est attesté depuis Homère, Iliade XXIII 173-174; cf. aussi Plutarque, Thémistocle X, 9-10 : il s'agit là de pratiques bien plus affectives que rituelles qui n'ont pas donné lieu à des actes sacrificiels. 
des squelettes de prématurés et de nouveau-nés ${ }^{89}$ les ossements de treize chiens ${ }^{90}$. Plaident pour une utilisation rituelle de ces animaux leur âge identique - excepté un spécimen d'un an environ, tous sont âgés de moins de six mois -, l'absence de toute pathologie apparente ${ }^{91}$ qui peut suggérer une sélection préalable comme le requérait tout sacrifice, et plus encore le démembrement quasi systématique de leurs corps ; en outre, l'une des tombes d'enfant accompagné d'ossements canins comportait un pot de cuisine (rempli d'os, d'huile d'olive et de fragments de vaisselle utilisée pour des libations) intentionnellement cassé et disposé avec soin - l'ouverture tournée vers la terre ${ }^{92}$, comme une offrande à des dieux chthoniens.

Quelques témoignages littéraires - latins et grecs - des Ier et IIè s. mentionnent aussi des chiens sacrifiés à Rome près de la porta Catularia ${ }^{93}$ et en 1'honneur de Genita $M a n a^{94}$, mais aussi lors de fêtes qui nous restent encore obscures par bien des aspects ${ }^{95}$ : les Robigalia ${ }^{96}$, les Lupercales ${ }^{97}$ et l'augurium canarium $^{98}$, le plus souvent, hélas, sans aucune description du rituel - hormis chez Ovide.

2. ... considérés partout comme des rituels à part entière ...

Si les sources littéraires, épigraphiques et archéologiques attestent la relative fréquence de rituels canins, encore faut-il être certain qu'il ne s'agisse pas de pratique magique ou superstitieuse.

\section{1. Dans la terminologie}

Les auteurs grecs emploient pour les sacrifices canins les mêmes verbes que pour les autres rituels sacrificiels : le plus souvent $\theta \cup ̉ \omega^{99}$, traditionnellement utilisé «pour désigner la consécration d'une offrande ${ }^{100}$, mais aussi $\kappa \alpha \theta \varepsilon \rho \rho \omega^{101}$ et $\varepsilon \dot{v} \tau \dot{\varepsilon} \mu \nu \omega^{102}$ qui souligne la position inclinée de la tête de l'animal avant son égorgement. Le chien est

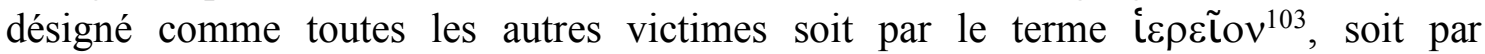

${ }^{89}$ Cf. D. Soren, T. Fenton, W. Birkby, 1998, p. 489.

${ }^{90}$ Rituels assez proches, semble-t-il, de ceux qui se sont déroulés sur l'agora d'Athènes.

${ }^{91}$ Cf. M. MacKinnon, 1998, p. 543.

${ }^{92}$ Cf. D. Soren, 1998, p. 620.

${ }^{93}$ P. Festus, p. 39 L.

${ }^{94}$ P. Festus, p. 358 L ; Pline l'Ancien, XXIX, 58 ; Plutarque, Questions Romaines 52.

95 Et dont la clé réside peut-être dans l'analyse du sacrifice canin (cf. D. Sabbatucci, 1988 , p. 139 : «probabilmente la sua presenza in questo rito se convenientemente spiegata, ci direbbe qualcosa di più e di meglio sui Robigalia »).

96 Ovide, Fastes IV 901-942 ; Columelle, De l'Agriculture X, 342-343. (Cf. D. Sabbatucci, 1988, p. 182 : « tutto è incerto quando si parla dei Robigalia »; F. Blaive, 1995, p. 279 évoque « cette épineuse question des Robigalia »).

97 Plutarque, Questions Romaines 68, 111.

98 P. Festus, p. 358 L. Pline l'Ancien, XVIII, 14. Le terme même d'augurium pose problème : cf. A. L. Prosdocimi, 1978, p. 761, A. L. Prosdocimi, 1996, p. 590.

${ }^{99}$ Plutarque, Questions Romaines 52 ; Pausanias, III, 14, 9.

${ }^{100}$ L. Bruidt Zaidman, P. Schmidt Pantel, 1991, p. 22.

101 Plutarque, Questions Romaines 68.

102 Plutarque, Questions Romaines 111.

${ }^{103}$ Pausanias, III, 14, 9. 
$\sigma \phi \alpha ́ \gamma 10 v^{104}$ s'il s'agit de mettre l'accent sur son égorgement et le sang qui coule, autrement dit sur son aspect chthonien ${ }^{105}$. Les écrivains romains évoquent, quant à eux, la res diuina ${ }^{106}$ ou le sacrificium ${ }^{107}$ d'une victima ${ }^{108}$ ou d'une hostia ${ }^{109}$ qui est immolata $^{110}$ : autant de termes que l'on retrouve communément dans toutes les descriptions sacrificielles ${ }^{111}$. Dans les Tables Eugubines, les mêmes verbes sont utilisés pour le sacrifice du chien et celui des autres animaux : ampentu ${ }^{112}$ («qu'il mette à mort»), purtuvitu ${ }^{113}$ (« qu'il porte en offrande »), kumultu ${ }^{114}$ («qu'il broie les restes »). Tant chez les Ombriens, les Romains que les Grecs, le champ lexical du sacrifice canin ne recèle aucune spécificité.

\section{2. Comme dans les gestes}

\section{2. 1. A Rome}

Il en va de même pour le déroulement de ces rituels. Les gestes et les mots convoqués aux Robigalia n'ont ainsi rien de très surprenant : à l'issue d'une procession en toge blanche, typique des sacrifices publics, l'officiant répand sur le foyer les traditionnels encens et vin avant d'offrir les exta tout en récitant, comme il est d'usage, une prière: "Rugueuse Robigo, épargne les plantes de Cérès et laisse frémir leurs pointes lisses à la surface du sol. Permets aux pousses de bénéficier d'influences astrales favorables et de se développer jusqu'à ce qu'elles deviennent mûres pour la faux. Ta puissance n'est pas négligeable: les blés que tu as marqués, le paysan les compte tristement parmi ses pertes. Cérès souffre moins des vents et des pluies, elle pâlit moins sous la brûlure d'un gel de marbre que si le soleil échauffe les chaumes humides : c'est alors que peut s'exercer ta colère, redoutable déesse. Grâce, je te prie, écarte tes mains râpeuses des moissons ; ne nuis pas aux cultures ; c'est assez de pouvoir nuire. [...] [G]arde-toi de faire violence à Cérès ; efface-toi, pour que le laboureur puisse toujours s'acquitter de ses vœux envers toi ». Cette supplique - certes sans doute retravaillée par

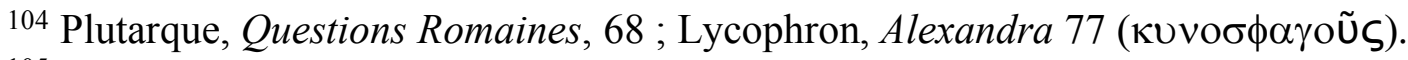

${ }^{105}$ Cf. L. Bruidt Zaidman, P. Schmidt Pantel, 1991, p. 24.

106 Pline l'Ancien, XXIX, 58.

${ }^{107}$ P. Festus, p. 358 L.

108 Ovide, Fastes 942.

109 Tite-Live, XL, 6, 1.

${ }^{110}$ P. Festus, p. 39 L ; P. Festus, p. 358 L.

111 Sacrificium, cf. par exemple Tite-Live, XXII, 1, 6 ; XXII, 57, 6 ; XXXVI, 30, 3 ; XXXVII, 9, 7 ; res diuina, cf. par exemple, Tite-Live, XXXI, 5, 3 et 7 ; XXXII, 9, 4 ; XXXVI, 1, 1-4, XXXVII, 3, 5-6 ; uictima, cf. par exemple Tite-Live, XXIX, 27, 5 ; hostia, cf. par exemple Tite-Live, XXVII, 25, 9 ; XXVII, 37, 15 ; XXVII, 16, 1 ; XXX, 27, 11-12 ; XXVII, 26, 13-14 ; immolare, cf. par exemple Tite-Live, XXI, 63, 13 ; XXII, 1, 19 ; XXVIII, 38, 8 ; XXX, 2, 13.

112 TE IIa 20 (chien) ; IIb 10, 11, 27 ; III 23, 27 ; Va 17.

113 TE Ia 18, 27, 30, 33 ; Ib 33, 39 ; IIa 7, 9, 24 et 29 (chien), 43 ; IIb 11, 17, 28 ; III 33, IV, 1, 4, 6, 16, 18, 20, 22, 31 ; Va 18 ; VIa 56 ; VIb 42 ; VIIa 43 ; VIb 16, 18, 23, 24, 37,38 ; VIIa 45.

114 TE Ia 34 ; Ib 37, 38 ; IIa 9, 10, 41 (chien), 42, IV 28, 29 ; VIb 17, 41, VIIa 39, 44, 45 .
} 
Ovide $^{115}$ - use de procédés stylistiques traditionnels dans les prières publiques comme en témoignent la prudente invocation initiale, les répétitions verbales, l'usage de l'impératif, et plus encore les nombreuses précautions oratoires destinées à ne pas offenser la divinité ; elle n'est en tout cas absolument pas marquée par la violence verbale $^{116}$ des formules traditionnelles d'exécration dont on l'a parfois rapprochée. Ce long texte demeure à l'abri des hyperboles usuelles dans le discours de la magie.

Le sacrifice canin pratiqué durant les Lupercales n'a rien non plus d'une obscure cérémonie : il se déroule pareillement en public, " à travers la ville ${ }^{117}$, dans le cadre d'une fête encadrée par la Cité et célébrée par l'une des principales confréries religieuses, en présence du prêtre le plus prestigieux de Rome - le flamen Dialis $^{118}$.

De même, la présence attestée d'ossements de chien mêlés à ceux d'autres animaux sacrifiés plus couramment comme les ovins, les porcins et les bovins, au sein de sanctuaires certes peu nombreux mais qui comptent parmi les plus prestigieux (comme celui de Vesta), au coeur même de la Cité, confirme que les sacrifices canins s'intégraient à l'ensemble des cérémonies civiques et devaient être accomplis comme les autres par les prêtres ou les magistrats, à la vue de tous, rite et recte. L'analyse ostéologique menée sur les restes canins de Satricum ${ }^{119}$ comme sur ceux de Lavello et de Poggio Gramignano ${ }^{120}$ a révélé aussi l'absence de toute pathologie chez ces animaux - indice peut-être d'une sélection (probatio) qui intervenait dans tous les sacrifices courants.

2. 2. 2. Dans le monde italique

A Gubbio, le sacrifice canin (tableau 2) reprend bon nombre d'éléments présents dans les autres rituels décrits par les Tables : il commence par l'observation des oiseaux (avis anzeriates ${ }^{121}$ ) comme la cérémonie de purification du mont Fisien ${ }^{122}$, nécessite que l'on apporte du feu sur un autel comme pour le sacrifice d'un porcelet à Iuvepatre ${ }^{123}$, s'accompagne de prières en silence (taçez) ${ }^{124}$ comme le sacrifice de trois agneaux à Tefre Iuuie ${ }^{125}$, celui de trois bœufs à Çerfe Marti ${ }^{126}$ ou encore celui de trois cochons à Prestate Çerfie Çerfe Marties ${ }^{127}$. Les adjectifs sakre (sacré), sevakne (sans

115 Cf. F. Bömer, 1958287 : « das gebet ist frei stilisiert»; C. Santini, 1991, p. 169 : « un libero rifacimento di Ovidio » mais «probabilmente vi affiorano alcuni elementi del testo arcaico della preghiera $»$.

116 Cf. F. Bömer, 1958, p. 289.

${ }^{117}$ Plutarque, Romulus 21, 7.

118 Cf. Ovide, Fastes II, 282 : «selon l'usage antique le flamen Dialis y assistait» ( «lamen ad haec prisco more Dialis erat »).

119 Cf. W. Prummel, 1996, p. 442.

${ }^{120}$ Cf. M. MacKinnon, 1998, p. 543.

121 TE IIa 17.

122 TE Ia 1-2 ; VIa 1-21.

123 TE III 21.

124 TE IIa 39.

125 TE Ia 26.

126 TE Ib 26.

127 TE Ib 28. C'est le cas aussi dans le sacrifice de trois génisses à Tuse Çerfie Çerfe Marties (TE Ib 32) et à Tuse Iuuie (TE Ib 44) et d'un bélier à Iuuie (TE IIa 7). 
défaut) ${ }^{128}$ appliqués au chien sont les mêmes que ceux attribués aux autres victimes : sakre est employé aussi pour les bovins ${ }^{129}$ et les ovins ${ }^{130}$ et peut même désigner à lui seul le porc, qualifié lui aussi souvent de sevakne ${ }^{131}$. Hormis le salu maletu (sel moulu), les offrandes complémentaires ( arvia $^{132}$, struhçla ${ }^{133}$, fikla ${ }^{134}$ ), les produits consacrants (puni ${ }^{135}, \operatorname{vin}^{136}$, onguent ${ }^{137}$ ), tout comme le matériel (mantrahklu ${ }^{138}$, veskla snata asnata ${ }^{139}$ ) interviennent dans d'autres rites ${ }^{140}$. L'intérêt porté aux supa ${ }^{141}$ du chien se révèle tout autant dans d'autres sacrifices animaux, à Trebe Iuvie ${ }^{142}$ ou à Fise Saçi ${ }^{143}$. La fosse (peřae ${ }^{144}$ ) au-dessus de laquelle est accomplie une vestiçia ${ }^{145}$ est

${ }^{128}$ Cet adjectif peut aussi s'appliquer aux objets rituels : il correspond très probablement aux expressions latines sine uitiis, sincerus (employé par exemple par Plaute, Men. 289 : porci sinceri) et peut être traduit par «sans défaut», cf. G. Devoto, 1967, p. 222 ; J. W. Poultney, 1959, p. 315.

129 TE IIa 5.

${ }^{130}$ TE IIa 6 ; III 8, 9, 12.

131 TE III 22.

132 Arvia a sans doute le sens de " céréales », «produits des champs» (cf. J. W. Poultney, 1959, p. 299 ; A. Ancillotti, R. Cerri, 1996, p. 166). Cet ingrédient intervient constamment dans les Tables : cf. TE Ia 3, 6, 9, 10, 12, 13, 16, 19, 23, 26, 27 ; Ib 3, 4, 6, 7, 25, 26, 28, 30, 32, 33, 43, 44 ; IIa 6, 7, 11, 12, 18, 24 ; IIb 8, 29 ; III 31 ; VIa 56, 58 ; VIb 1, 3, 20, 22, 44, 45 ; VIIa 4, 7, 42, 53.

${ }^{133}$ Ce terme désigne sûrement un type de gâteau sacrificiel (cf. latin strues) qui intervient dans d'autres rites : TE IIa 18, 28, 41 ; III 34 ; IV 1, 4 ; VIa 59; VIb 5, 23 ; VIIa 8, 42, 54.

134 Fikla est sans doute aussi une sorte de gâteau sacrificiel (cf. latin fitilla) offert également à d'autres occasions : TE IIa 18, 29, 41 ; VIa 56, 59 ; VIb 2, 4, 20, 23, 44, 46 ; VIIa 4, 8, 54 ; VIIa 42.

135 Vraisemblablement une sorte de farine sacrée: la puni peut sans doute être rapprochée de la mola salsa des Romains (A. L. Prosdocimi, 1984, p. 3331-3332; A. Ancillotti, R. Cerri, 1996, p. 168) : puni serait issu de *polni qui peut être relié au latin pollen - la fleur de farine. Cet ingrédient permet la consécration.

136 TE Ia 4, 22 ; Ib 6 ; IIa 18, 25, 39, 40 ; IIb 10, 14, 20 ; VIa 57 ; VIb 19, 46.

137 TE IIa 19, 34, 38 ; IV 13 (umtu).

138 Sans doute une pièce de tissu (cf. J. W. Poultney, 1959, p. 311) : TE IIa 19; IIb 16 ; VIb 4.

139 Sans doute de la vaisselle pour les liquides et les non liquides (cf. J. W. Poultney, 1959, p. 331) : TE Ib 29, 37 ; IIa 31, 34, 37 ; IIb 18 ; IV 9, 24 ; VIIa 9, 10, 18, 21, 24, $26,32,34$.

${ }^{140}$ A l'inverse, dans l'Huntia on ne retrouve pas tous les gâteaux sacrificiels des autres rites : tenzitim (TE Ib 6 ; VIb 46), petenata (TE IV 4), arçlata (TE VIb 22), fasiu (TE IIa 12 ; VIb 2, 44).

141 TE IIa 22, 30, 32. Il s'agit vraisemblablement des entrailles basses, cf. J. W. Poultney, 1959, p. 324.

142 TE Ia 9.

143 TE Ia 16.

144 TE IIa 22.

145 TE IIa 27 ; VIb 6. A entendre sans doute dans le sens de «libation» (cf. J. W. Poultney, 1959, p. 331 qui reste néanmoins très prudent, p. 254 : « In no case can the precise nature of the vestiçia be determined »). La signification « impasto » (pâte, 
nécessaire aussi dans l'accomplissement des sacrifices à Stafli Iuvesmik ${ }^{146}$, à Tikamne Iuvie $^{147}$ et à Puemune Pupřike ${ }^{148}$. La mise à mort (ampentu ${ }^{149}$ ) du chien ressemble beaucoup à celle des autres victimes - le bouc à Saçi ${ }^{150}$, le $\operatorname{cochon}^{151}$ et le bœuf ${ }^{152}$ à Iuvepatre, le mouton à Puemune Pupřike ${ }^{153}$. La consécration (purtuvitu) ${ }^{154}$ comme la destruction finale (kumultu) ${ }^{155}$ des offrandes se retrouvent à l'identique dans les autres sacrifices ${ }^{156}$. Même l'enterrement du chien (ou du moins de ce qui en reste) à la fin de l'Huntia n'a rien d'inédit: sont inhumés aussi les trois agneaux offerts à Tefre Iuvie $^{157}$, le bélier à Iuvie ${ }^{158}$ et le mouton à Puemune Pupřike ${ }^{159}$. L'absence de consommation de la chair, qui est mise en terre à l'issue de la cérémonie, ne s'explique donc pas par la nature de l'animal. Le sacrifice du chien ne paraît ainsi pas bénéficier d'un traitement particulier à Gubbio : il est en tout point conforme aux autres rituels. Accompli à date fixe (en lien avec les cycles lunaires ${ }^{160}$ ), il est de plus encadré par les autorités civiques, en la personne du questeur - véritable garant de sa bonne exécution ${ }^{161}$.

A Torre di Satriano, comme à l'embouchure du Sele, la présence des os de chiens aux côtés de ceux d'autres animaux plus couramment sacrifiés (bovins, ovins, caprins), au sein de sanctuaires à l'évidence communautaires, atteste tout autant du caractère public (et sans doute régulier) de ces rituels.

\section{2. 3. En Grèce}

En Grèce, le rituel mené par l'armée macédonienne, conviée à défiler entre les deux moitiés d'une chienne, s'avère tout aussi exempt de caractère occulte. Réalisé publiquement et régulièrement ${ }^{162}$, il consiste en un cortège parfaitement hiérarchisé qui reflète l'organisation sociale : « en tête du cortège sont portés les armes et les emblèmes de tous les rois de Macédoine, depuis la plus lointaine origine du royaume; puis vient le roi lui-même, accompagné de ses enfants ; tout de suite après viennent la cohorte royale

mélange) proposée par A. Ancillotti, R. Cerri, 1996, p. 156 est plus contestable, surtout dans ce contexte (où le rite s'effectue en relation avec une fosse).

146 TE Ia 32.

147 TE IIa 9.

148 TE III 33.

149 TE IIa 20 ; IIb 10, 11, 27 ; III 23, 27 ; Va 17.

150 TE IIb 10.

151 TE III 23.

152 TE IIb 27.

153 TE III 27.

154 TE IIa 29.

155 TE IIa 41-42.

156 Cf. TE Ib 39; VIIa 45. Sur les différentes étapes des sacrifices des Tables Eugubines, cf. A. L. Prosdocimi, 1984.

157 TE Ia 24 / VIb 22.

158 TE IIa 6.

159 TE III 31-32.

160 TE IIa 16.

161 TE IIa 44.

162 Tite-Live, XL, 6, 1 : « on arriva alors à la date de lustration de l'armée ». 
et les gardes du corps; le reste, le gros de la troupe des Macédoniens, ferme la marche ». Le rite se déroule dans une ambiance solennelle mais sans aucun signe de peur, ni aucune manifestation de soumission à une quelconque divinité comme il est courant dans les pratiques superstitieuses. De même, les rites canins révélés par le contenu du puits de l'agora d'Athènes excluent, par leur localisation, toute pratique qui aurait échappé au contrôle de la cité.

\section{3. Mais de plus en plus désuets}

Ainsi, l'utilisation sacrificielle du chien ne relève aucunement de manipulations magiques ou mystérieuses, mais répond au contraire à de rigoureux impératifs rituels, caractéristiques des religions publiques ${ }^{163}$.

Dans cette perspective, comment expliquer tant l'étonnement d'Ovide devant cette victime qu'il qualifie de noua et même d'obscena ${ }^{164}$ que l'intérêt intrigué de Plutarque face à cette "particularité ${ }^{165}$ ? Sans doute parce que cette pratique - courante à l'époque médio-républicaine - est progressivement tombée en désuétude, ne survivant à l'époque impériale que dans le cadre d'antiques fêtes (les Robigalia, l'augurium canarium, les Lupercales) et à destination souvent de divinités reléguées désormais au second plan, comme Genita Mana ou Robigo. En témoigne la datation - antérieure ou contemporaine à la première moitié du IIIe s. av. J.-C. - de quasiment tous les ossements canins retrouvés à Rome (dans la zone de Sant'Omobono, près de la porta Mugonia et à proximité du Lapis Niger), et dans l'ager romanus au pied des remparts de Paestum et d'Ariminum, à Lavello comme à Satricum (tableau 1). C'est d'ailleurs sur les écrits de Plaute que Pline l'Ancien s'appuie pour rappeler combien la consommation de viande de chien était fréquente au temps du dramaturge «dans les repas inauguraux des magistrats ${ }^{166}$, sous-entendant qu'elle est devenue un mets plus rare à son époque. Vraisemblablement, la nouvelle image dont bénéficie le chien, perçu de plus en plus par les Romains comme un animal familier, n'est pas étrangère à cette évolution : il paraît sans doute de plus en plus incongru de sacrifier des bêtes désormais intégrées à la familia ${ }^{167}$ au point que leur sont même édifiées des tombes ${ }^{168}$ (fig. 9) et

${ }^{163}$ Contre l'affirmation de C. Mainoldi, 1984, p. 52 : « Le sacrifice du chien se présente en général, sauf dans quelques cas, comme un rite privé qui se situe dans le domaine de la famille ».

164 Ovide, Fastes VI, 158-159. Obscena peut être expliqué par une annotation du calendrier de Préneste qui mentionne les Robigalia comme la fête des lenones $\left(C I L \mathrm{I}^{2}\right.$ 317).

165 Plutarque, Romulus 21 : « une particularité de cette fête, c'est que les Luperques y sacrifient aussi un chien $\gg$.

166 Pline l'Ancien, XXIX, 58.

167 Comme le montre, par exemple, le portrait dithyrambique que dresse Martial (Epigrammes I, 109, 1-20) d'une petite chienne : " Issa est plus coquine que le moineau de Lesbie, Issa est plus pure qu'un baiser de colombe, Issa est plus caressante que toutes les fillettes, Issa est plus précieuse que les perles de l'Inde, Issa est la petite chienne chérie de Publius. Si elle se plaint, vous croiriez qu'elle parle; elle comprend la tristesse et la joie. Elle repose appuyée sur la nuque et elle dort de telle sorte qu'on ne l'entend même pas respirer. [...] Pour que son heure dernière ne la lui enlève pas tout à fait, Publius en reproduit l'image sur un tableau où tu verras une Issa si ressemblante que même Issa ne se ressemble pas autant à elle-même ». Cf. aussi J. M. C. Toynbee, 1973, p. 120. 
rédigées des épitaphes déchirantes: "Comme elle était douce, comme elle était gentille ! quand elle était vivante, elle dormait dans mes bras ... Quel malheur Myia que tu sois morte ! ${ }^{169}$ En Grèce, où le regard sur le chien s'est lui aussi transformé ${ }^{170}$, les rituels canins semblent avoir connu la même désaffection progressive : fréquemment accomplis à une haute époque comme en attestent les découvertes archéologiques, ne suscitant encore aucune surprise dans l'Athènes du Ves. av. J.-C. ainsi qu'en témoignent le théâtre ( $d$ 'Aristophane ${ }^{171}$ ) et la peinture (sur un lécythe ${ }^{172}$ ), ils ne manquent pas d'être relevés, à titre de curiosités, par les auteurs tardifs, étonnés de leur survivance - bien souvent là aussi dans le cadre de rituels ancestraux et quelque peu surannés, comme l'étaient les cérémonies spartiates d'initiation ${ }^{173}$.

Actuels ou vieillis, les sacrifices canins ne laissent pas d'obéir quoi qu'il en soit à de minutieuses règles rituelles, nécessairement divergentes d'une communauté à l'autre.

3. ... fort différents d'une communauté à l'autre ...

En dépit des efforts de nombreux commentateurs pour rapprocher et assimiler certains d'entre eux, ces rites canins présentent de l'un à l'autre des dissemblances significatives.

\section{1. Des acteurs, des lieux et des moments dissemblables}

Les chiens, il est vrai, sont sacrifiés quasi systématiquement en l'honneur de divinités (tableau 1) dont la place est mineure dans les panthéons des communautés concernées. Pour autant, il semble bien difficile a priori de dégager de claires convergences entre toutes ces figures divines: certaines semblent avoir une

${ }^{168}$ Cf. J. M. C. Toynbee, 1973, p. 108-122.

${ }^{169}$ CIL VI, 1609 (datée du IIè s.).

${ }^{170} \mathrm{Cf}$. Elien, Histoire variée 8,4 : « Poliarque d'Athènes était, dit-on, parvenu à un tel point de mollesse qu'il organisait des funérailles publiques à la mort de ses chiens et de ses coqs préférés. Il invitait ses amis à ces enterrements, ensevelissait ces animaux à grands frais et dressait pour eux des cippes sur lesquels il faisait graver des épitaphes ». Cf. sur cette évolution, les commentaires de C. Mainoldi, 1984, p. 179-180 qui a montré combien s'est modifiée l'image du chien dans la littérature hellène depuis Homère jusqu'à l'époque classique : « la tradition littéraire tend à effacer, surtout à l'époque classique, l'aspect "monstrueux" du chien lié aux enfers, pour en faire surtout un collaborateur de l'homme dans le domaine de la domestication. [...] Le chien représente désormais l'état domestique, l'intégration à la cité ». L'art funéraire montre, lui aussi, la nouvelle proximité qui s'installe entre les Grecs et leurs chiens : cf. G. Herrlinger, 1930 (qui dresse l'inventaire des épitaphes dédiées aux chiens); L. P. Day, 1984, p. 29 («The dog sacrifices in the Late Helladic tombs thus show a different attitude towards dogs from that of either earlier or later periods. Dogs seem to have been valued for their usefulness in the hunt, as guardians or as companions, but nowhere do we see the sort of sentimental regard for them as pets displayed by the later Greeks »).

${ }^{171}$ Aristophane, fr. 204.

${ }^{172}$ Cf. L. Deubner, 1960, p. 2.

173 L'intégration des Italiques dans le cadre romain au cours de la période médiorépublicaine rend difficile l'appréhension d'une semblable évolution chez ces communautés. 
physionomie chthonienne (Hécate, Énodie), d'autres guerrière (Ényalios) ou agraire (Robigo), d'autres encore paraissent avoir partie liée aux femmes et à la fécondité (Genita Mana, Ilithyie).

La diversité des officiants - quand ils sont mentionnés - s'avère encore plus frappante. Si à Sparte, le rite est accompli par deux groupes d'éphèbes ${ }^{174}$, à Rome, aux Robigalia ${ }^{175}$, il l'est par le flamen Quirinalis (l'un des trois flamines majeurs) accompagné de nombreux participants et aux Lupercalia par la confrérie des Luperques ${ }^{176}$, en présence du flamen Dialis, tandis que l'Huntia des frères atiédiens est célébrée par l'ařfertur, l'officiant requis pour toutes les cérémonies ${ }^{177}$.

Et s'il s'agit pour la plupart de rites publics, leur lieu d'exécution apparaît fort hétéroclite : à l'extérieur de la cité de Sparte ${ }^{178}$, sur le champ de bataille des armées macédoniennes ${ }^{179}$, mais aussi dans un bois sacré aux limites de la cité romaine ${ }^{180}$, près de portes ${ }^{181}$ et de murailles ${ }^{182}$, et bien sûr au sein des sanctuaires. Le moment de leur réalisation est tout aussi varié, l'impératif temporel pouvant concerner l'heure (la nuit à Colophon et à Sparte ${ }^{183}$ ou avant le combat en Macédoine ${ }^{184}$ ), la date mensuelle (au moment de la pleine lune à Gubbio ${ }^{185}$ ) ou annuelle («pendant le mois des purifications $\rangle^{186}$ pour les Lupercales, au milieu du printemps pour les Robigalia ${ }^{187}$, et «quand les moissons sont parvenues presque à maturité » ${ }^{188}$ pour l'augurium canarium).

Les chiens eux-mêmes ne sont pas tous identiques d'un rite à l'autre. Souvent jeunes, non encore sevrés, dans les sacrifices à Hécate ${ }^{189}$, à Ényalios ${ }^{190}$, à Énodie ${ }^{191}$ comme à Hunte Iuuie $^{192}$ et à Genita Mana ${ }^{193}$, et dans les rituels de Poggio Gramignano ${ }^{194}$, il s'agit parfois aussi de spécimens adultes tant en terre grecque ${ }^{195}$ qu'à Rome ${ }^{196}$ et en

${ }^{174}$ Pausanias, III, 14, 9.
${ }^{175}$ Ovide, Fastes IV, 907.
${ }^{176}$ Plutarque, Romulus, 21 .
${ }^{177}$ Il réalise la prise d'auspices et les sacrifices lors de la purification du Mont Fisien (TE Ia 1-Ib 9) et durant la lustration (TE Ib 10-45) ; il mène les sacrifices en cas d'auspices défavorables (TE IIa 1-14). C'est lui aussi qui est en charge des rites accomplis durant la cérémonie « décuriale » (TE IIb 1-21).

178 Pausanias, III, 14, 9.

179 Tite-Live, XL, 6, 1-3.

180 Ovide, Fastes 907.

${ }^{181}$ P. Festus, p. 39 L.

182 A Paestum, comme à Ariminum : cf. R. Robert, 1993.

183 Pausanias, III, 14, 9.

184 Tite-Live, XL, 6, 1-3.

185 TE IIa 15.

186 Plutarque, Questions Romaines, 68.

187 Ovide, Fastes IV 902-903.

188 P. Festus, p. 358 L.

189 Aristophane, fr. 204 ; Plutarque, Questions Romaines, 68.

${ }^{190}$ Plutarque, Questions Romaines, 111.

${ }^{191}$ Pausanias, III, 14, 9.

192 TE IIa 15-44.

193 Pline l'Ancien, XXIX, 58.

${ }^{194}$ Cf. M. MacKinnon, 1998, 542.

195 Plutarque, Questions romaines, 52 ; Pausanias, VI, 2, 4-5 ; Tite-Live, XL, 6, 1-3 ;

Quinte-Curce, X, 9-12. 
Etrurie où l'examen ostéologique du chien de Pyrgi a conclu à l'âge approximatif d'un $\mathrm{an}^{197}$. La victime est généralement un mâle, mais parfois aussi une femelle, par exemple dans le sacrifice à Enodie accompli par les habitants de Colophon ${ }^{198}$ ou dans les rituels macédoniens ${ }^{199}$ et certaines pratiques romaines (accomplies près de la porta Catularia $^{200}$ et aux Robigalia ${ }^{201}$ ). Et même si la situation la plus fréquente est celle d'une victime unique, plusieurs chiens peuvent aussi être offerts au cours d'une même cérémonie : en Grèce dans des rituels de purification ${ }^{202}$ et à Rome lors de l'augurium canarium $^{203}$ - pour lequel les animaux doivent être obligatoirement roux ${ }^{204}$, alors que la couleur paraît indifférente dans tous les autres rituels canins ${ }^{205}$. Enfin, si dans toutes les autres cérémonies, ces bêtes sont des victimes exclusives, le flamen Quirinalis offre à Robigo conjointement un chien et une brebis ${ }^{206}$.

\section{2. Des séquences rituelles spécifiques}

Mais les différences majeures résident évidemment dans l'enchaînement et le contenu des séquences rituelles. Dans le monde grec lui-même, il n'y a rien de commun entre les cérémonies très particulières en l'honneur d'Hécate, relatées par Plutarque, durant lesquelles, « ils apportent à Hécate des jeunes chiens avec d'autres moyens de purification et frottent tout autour avec les jeunes chiens ceux qui ont besoin d'une purification $»^{207}$, et les rites de purification béotiens et macédoniens au cours desquels les participants «passent entre les deux parties d'un chien qu'ils ont coupé par le milieu $»^{208}$, ni entre les rites initiatiques des éphèbes de Sparte ${ }^{209}$ et les rites nocturnes des Colophoniens ${ }^{210}$.

Il est bien difficile aussi de trouver des énoncés rituels communs entre l'Huntia et les Robigalia qui ont souvent été rapprochées ${ }^{211}$ : le rite pratiqué par l'ařfertur est

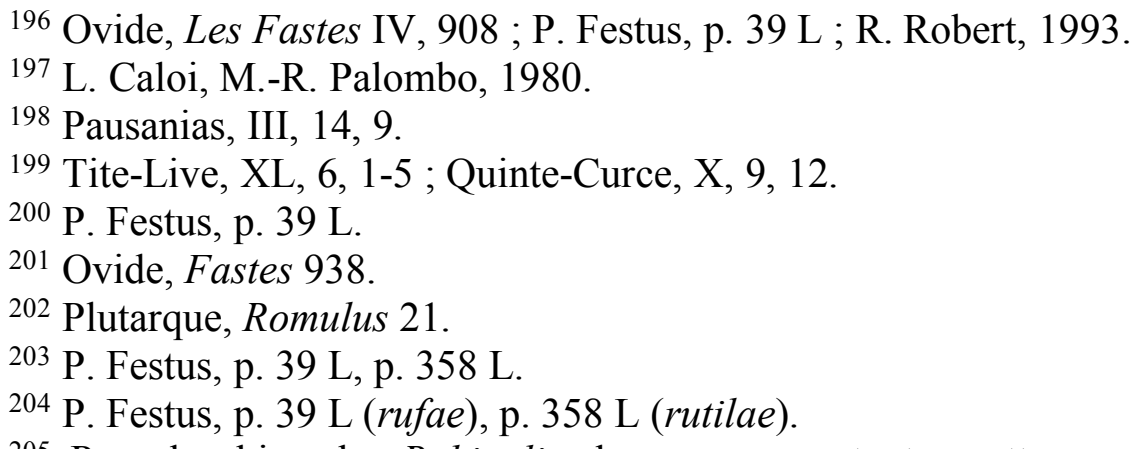

205 Pour le chien des Robigalia, les sources restent muettes quant à sa couleur (cf. F. Blaive, 1995, p. 284), ce qui n'a pas empêché les commentateurs modernes, séduits par la « magie sympathique » (W. Warde Fowler, 1925, p. 90), de les décrire « roux », par analogie avec l'augurium canarium (cf. par exemple, N. J. Zagarianis, 1975, p. 322). C'est ce qui a légitimé un rapprochement entre les Robigalia et les Cerialia du 19 avril durant lesquelles entraient en scène - sans être sacrifiés - d'autres animaux roux - les renards (cf. J.-N. Robert, 1985, p. 301-303 et D. Porte, 1985, p. 156-158, partisans de placer le lâcher de renards aux Robigalia. Contre de telles thèses, il faut relire H. Le Bonniec, 1958, p. 119 et J. Bayet, 1971, p. 100)!

206 Ovide, Fastes 908.

${ }^{207}$ Plutarque, Questions Romaines 68.

${ }^{208}$ Plutarque, Questions Romaines, 111 ; aussi Tite-Live, XL, 6, 1-3.

209 Pausanias, III, 14, 9.

210 Pausanias, III, 14, 9.

${ }^{211}$ Cf. R. Cirilli, 1912, p. 330. 
beaucoup plus complexe (et précis) que le sacrifice mené par le flamen. Les offrandes complémentaires et les produits consacrants - hormis le vin - sont loin d'être tous les mêmes : gâteau struhçla, gâteau fikla, farine, sel moulu, onguent en l'honneur d'Hunte Iuuie; encens seulement pour Robigo. Alors que les rites ombriens exigent l'observation préalable des oiseaux ${ }^{212}$ ainsi que l'exécution d'une danse ${ }^{213}$, la fête romaine commence par une procession ${ }^{214}$; et si les prières accompagnent les gestes de l'officiant tant à Gubbio qu'à Rome (ce qui est d'ailleurs le propre de tous les rituels ombriens et romains), elles n'ont pas la même physionomie : au cours de l'Huntia une invocation très courte ${ }^{215}$ se superpose à la danse, tandis qu'une supplication amplement développée ${ }^{216}$ précède l'offrande des exta par le flamine.

Il est tout aussi abusif d'assimiler l'Huntia à l'augurium canarium comme le fait par exemple A. L. Prosdocimi ${ }^{217}$ en rapprochant le texte de Pline l'Ancien ${ }^{218}$ des lignes IIa 15-16 des Tables de Gubbio. La relative proximité textuelle qu'il met en évidence ${ }^{219}$ (katle tiçel rappelant augurio agendo; stakaz est, dies constituantur; antermenzaru çersiaru, priusquam frumenta uaginis exeant nec antequam in uaginis perueniant) ne veut pas dire analogie rituelle. D'ailleurs le terme tiçel peut sans doute signifier "déclaration, proclamation solennelle ${ }^{220}$, plus difficilement recouvrir le sens rituel précis - et complexe ${ }^{221}$ - d'augurium. La cérémonie romaine, sur laquelle les textes ne fournissent qu'un éclairage partiel, consiste en l'immolation non pas d'un seul chien à la couleur indéterminée comme à Gubbio, mais de plusieurs chiennes rousses (rutilae canes $^{222}$ ), à proximité de la porta Catularia; et alors que l'Huntia est réalisée par l'officiant habituel - l'ařfertur, sans doute l'augurium canarium était-il accompli par les augures ${ }^{223}$ comme l'était l'augurium salutis $^{224}$ et comme le suggère l'expression tirée des commentaires pontificaux - augurium agere traditionnellement employée pour de tels actes ${ }^{225}$. Mais surtout le contexte diffère : explicitement agraire dans le rituel romain (en lien avec la bonne croissance du grain ${ }^{226}$ ), il est plus vraisemblablement

\footnotetext{
212 TE IIa 17.

213 TE IIa 31.

214 Ovide, Fastes 913.

215 TE IIa 25.

${ }^{216}$ Ovide, Fastes 918-940.
}

217 A. L. Prosdocimi, 1978, p. 713. Cf. aussi C. Santini, 1991, p. 176 : « L'augurium canarium trova $[. .$.$] una esatta corrispondenza nelle dichiarazione del cane»; il$ considère même l'épi évoqué par Pline l'Ancien (XVIII, 14) «iconograficamente assimilabili all'obelisco [spina] del rituale eugubino ».

${ }^{218}$ Pline l'Ancien, XVIII, 14.

219 A. L. Prosdocimi, 1978, p. 761.

${ }^{220}$ Cf. G. Devoto, 1948, p. 59 ; A. L. Prosdocimi, 1978, p. 715 ; A. Ancillotti, R. Cerri, 1996, p. 421.

${ }^{221}$ Cf. G. Dumézil, 1987, p. 585.

${ }^{222}$ P. Festus, p. 358 L.

223 Les augures pouvaient accomplir des rituels sacrificiels: ainsi, sur l'Arx, cf. J. Scheid, 1998, p. 114.

${ }^{224}$ Cérémonie « qui avait lieu en période de paix totale et portait sur le succès du peuple romain pendant l'année à venir », J. Scheid, 1998, p. 114.

${ }^{225}$ Par exemple Varron, L. L., VI, 42 ; Cicéron, De Diuinatione, I, 32. Cf. L. Delatte, 1937, p. 100.

${ }^{226}$ P. Festus, p. 39 L, 13-16 : ad placendum caniculae sidus frugibus inimicum rufae canes immolabantur, ut fruges flauescentes ad maturitatem perducerentur. Pline 
funéraire $^{227}$ dans la cérémonie ombrienne comme le laissent supposer son aspect éminemment gentilice 228 et la physionomie du dieu honoré ${ }^{229}$.

Le sort réservé au chien à la fin du sacrifice est bien différent aussi selon les lieux et les circonstances. Si la plupart des communautés s'y refusent, quelques-unes en consomment : ainsi, à Sardes où l'on découvert les restes de trente-six chiots d'un mois environ, écorchés, vidés, découpés et vraisemblablement cuisinés ${ }^{230}$; mais aussi à Rome, au moins à la période médio-républicaine, comme en témoigne Pline l'Ancien : " on sacrifie à Genita Mana avec de petits chiens et, aujourd'hui encore, on sert leur viande dans les repas donnés en l'honneur des dieux. L'usage était même traditionnel dans les repas inauguraux des magistrats, comme le montrent les comédies de Plaute $»^{231}$.

\section{3. Des objectifs contrastés}

A lire les auteurs antiques, les rituels canins n'ont apparemment pas non plus les mêmes finalités. Ils sont pratiqués souvent à des fins propitiatoires : pour éviter que la rouille n'endommage les céréales lors des Robigalia ${ }^{232}$, pour se concilier Hunte Iuuie au cours de 1'Huntia $^{233}$ ou pour faciliter les accouchements ${ }^{234}$ lors de sacrifices à Genita Mana. Ils peuvent aussi avoir une visée divinatrice dans certaines régions de Grèce, où, selon Pausanias, un devin éléen pratique « une divination particulière fondée sur les entrailles de chien $»^{235}$ et sans doute à Rome dans le rite de l'augurium

l'Ancien, XVIII, 14 : priusquam frumenta uaginis exeant, nec antequam in uaginas perueniant. P. Festus, p. $358 \mathrm{~L}$ : immolantur, ut ait Ateius Capito, canario sacrificio pro frugibus deprecandae saeuitiae causa sideris caniculae. Il est pour autant abusif d'écrire comme A. L. Prosdocimi, 1996 que les sacrifices canins à Rome sont liés au cycle cérérien : ceux qui interviennent aux Lupercales, ceux qui ont été accomplis à la porta Mugonia, devant les murailles d'Ariminum et de Paestum ne peuvent y être rattachés.

${ }^{227}$ Considérant l'Huntia comme une cérémonie agraire, A. L. Prosdocimi, 1978, p. 713 y voit l'équivalent de l'ambarualia: le trait majeur de la cérémonie romaine - la circumambulation - n'a pourtant aucun correspondant dans le rituel ombrien.

228 TE IIa 20-21 : Hunte Iuvie ampentu katlu / sakre sevakne petruniaper natine fratru atiieřiu («Qu'il abatte en l'honneur de Hunte Iuvie un chien sans défaut sacré pour la lignée Petrunia de la confraternité des Atiédiens »). TE IIa 34-35 : hunte iuvie vestikatu petruniapert natine fratru atiieřiu (" qu' il fasse une libation à Hunte Iuuie pour la famille Petrunia de la confraternité des Atiédiens »).

${ }^{229}$ Cf. infra p. Quant au terme çersiaru que certains mettent en relation avec Cérès, il désigne plutôt une période mensuelle, un peu équivalente aux calendes (cf. G. Devoto, 1962, p. 321 ; V. Pisani, 1964, p. 197).

${ }^{230}$ Selon l'éditeur de cette découverte (C. H. Greenewalt, 1978, p. 1), il s'agit de restes de repas rituels.

${ }^{231}$ Pline l'Ancien, XXIX, 58. A cette époque, le chien était d'ailleurs considéré comme un mets alimentaire courant (cf. P. Festus, p. 39 L: Plaute qui « rapporte dans le Saturion que les Romains consommaient fréquemment de la viande de petits chiens ».)

232 Ovide, Fastes 908-942.

233 TE IIa 15-44.

${ }^{234}$ Plutarque, Questions Romaines 52.

${ }^{235}$ Pausanias, VI, 2, 4-5. 
canarium $^{236}$. Si l'on en croit Plutarque, ils sont accomplis aussi dans un but purificateur, tant dans les rites guerriers des Macédoniens que durant les Lupercales ${ }^{237}$.

A l'évidence, chaque communauté fait du chien une utilisation rituelle qui lui est propre, dont le détail demeure souvent bien obscur.

\section{4. ... avec pourtant d'éclairantes similitudes}

La clé d'une meilleure compréhension de ces rituels canins semble se trouver dans l'analyse approfondie des figures divines concernées. Toutes les divinités honorées par le sacrifice d'un chien ont en effet en commun une physionomie très particulière ${ }^{238}$ dont la caractéristique essentielle est l'ambivalence, rappelée bien souvent par la formation même de leur nom.

4. 1. De l'ambivalence des dieux ...

\section{1. 1. En Ombrie}

Le dieu ombrien Hunte Iuuie en fournit la plus claire démonstration. Cette figure n'intervient que dans la cérémonie de l'Huntia $^{239}$ dont l'appellation même dérive de son nom et dans laquelle il règne sans partage, alors qu'abondent les divinités dans toutes les autres séquences rituelles: huit dans la cérémonie purificatoire du mont Fisien $^{240}$ et lors des rites pratiqués en cas d'auspices défavorables ${ }^{241}$, quatre durant la lustration du peuple d'Iguvium ${ }^{242}$ et deux pendant la « fête décuriale $»^{243}$. Hunte Iuuie imprègne de sa seule présence le rite tout entier. Aussi, la compréhension de sa nature pourrait sans doute éclairer la signification des gestes et des paroles mis en œuvre tout au long de cette cérémonie.

La formation binaire de son nom recèle un paradoxe. Hunte - que l'on retrouve dans un autre théonyme (Hunte Çefi en écriture "indigène »" ${ }^{244}$, Honde Serfi en alphabet latin $^{245}$ ) - dériverait, selon les interprétations les plus répandues et les plus crédibles de * $\hat{g h o m-t o-~(« q u i ~ s e ~ t r o u v e ~ d e s s o u s, ~ d a n s ~ l e ~ s o l ~}{ }^{246}$ ) renvoyant ainsi à la terre ${ }^{247}$, plus

\footnotetext{
${ }^{236}$ P. Festus, p. 358 L ; Pline l'Ancien, XVIII, 14.

${ }^{237}$ Plutarque, Questions Romaines 111 ; Romulus 21.

${ }^{238}$ Ces divinités ne peuvent en aucun cas se réduire à des figures de déesses-mères, image dans laquelle de nombreux commentateurs les ont trop souvent cantonnées : cf. J. De Grossi Mazzorin, 2001, p. 80 qui parle de « divinità femminili protettrici della donna e associate al concetto di procreazione e crescita »; surtout A. Gianferrari, 1995, p. 137 qui recherche derrière ces figures divines « una divinità originaria » qu'il croit voir même dans la déesse Robigo : " dietro la dea Robigo di età classica si celi una figura primitiva di respiro ben maggiore $»$.

239 TE IIa 20, 34.

240 TE Ia $1-$ Ib 9.

241 TE IIa 1-45.

242 TE Ib 10-45.

243 TE IIb 1-21.

$244 \mathrm{TE} \mathrm{Ib} 4$.

245 TE VI b 45.

246 J. Untermann, 2000, p. 303 ; ainsi J. W. Poultney, 1959, p. 88, G. Devoto, 1962, p.

257. Voir A. Ancillotti, R. Cerri, 1996, p. 372.
} 
exactement au monde du sous-sol, de l'humus, écriraient les Romains: sans aller jusqu'à l'interprétation trop primitiviste de G. Devoto ${ }^{248}$ qui évoque « una specie di Terra divinizzata », on peut sans crainte parler d'un dieu chthonien. La deuxième partie du théonyme est encore plus transparente : Iuuie rappelle le Jupiter romain, renvoie à l'idée de lumière et aux espaces célestes, bien éloignés des sphères souterraines. Hunte Iuuie, en un oxymore surprenant, réunit donc deux aspects opposés, ce qui n'est pas le cas de l'association d'Hunte et de $\mathbf{C C e f i}^{249}$ plus « logique » en ce qu'elle réunit un dieu du sous-sol et une déesse de la terre (Çefi rappelle la Cérès romaine, la Kerrí osque), régulièrement dotée d'un visage infernal ${ }^{250}$.

Toute l'action rituelle de l'Huntia s'articule autour de cette ambivalence, la fait vivre et la martèle. Les gestes obéissent en effet à un balancement inégalitaire mais constant entre les deux aspects d'Hunte Iuvie, entre le sol et le ciel.

Le rite commence par la demande d'acquiescement du dieu jovien - maitre du ciel et des oiseaux comme son homologue romain - et se termine par l'enterrement du chien, remis ainsi au monde souterrain d'Hunte.

Si la fosse (peřae), au-dessus de laquelle est accomplie une vestiçia (libation), convient particulièrement à Hunte, la spina auprès de laquelle se déroule la deuxième phase rituelle (tableau 2) paraît davantage rattachée à Iuuie. Cet élément cultuel a souvent ${ }^{251}$ été considéré comme une image divine en pierre, proche du signum romain ; il pourrait s'agir d'une pierre - cippe ou colonne - plantée dans la terre, en forme de pointe, d' "épine » comme le suggère son homonyme latin ${ }^{252}$ : à l'appellation trop connotée ${ }^{253}$ de «menhir ${ }^{254}$ doit être préféré le terme « obélisque ${ }^{255}$, d'autant qu'il existe à quelques dizaines de kilomètres de Gubbio, dans les nécropoles étrusques de Pérouse comme celle de San Giuliano, des cippes en forme de colonne ou d'obélisque, d'une taille parfois monumentale ${ }^{256}$, à proximité desquels étaient réalisées offrandes et libations ${ }^{257}$, comme l'a révélé la découverte de débris de $\operatorname{vases}^{258}$ (fig. 10, 11) : ces colonnes n'avaient donc pas uniquement une fonction commémorative. Comment ne pas songer non plus aux cippes en tuf - couramment appelés iuuilas ${ }^{259}$ - du fondo Paturelli, expressément reliés à une divinité jovienne, dans un contexte gentilice ${ }^{260}$

${ }^{247}$ Cf. G. B. Pighi, 1954, p. 229 : « il senso sarà « terrenus, terrestris », qualcosa come gli dèi medioxumi tra gl'inferi e i superi di Plaut. Cist. $512 »$.

${ }^{248}$ G. Devoto, 1948, p. 15.

$249 \mathrm{TE} \mathrm{Ib} 4$.

${ }^{250}$ Cf. G. Dumézil, 1987, p. 379.

${ }^{251}$ Cf. J. Untermann, 2000, p. 693 qui fait l'inventaire des diverses interprétations.

${ }^{252}$ Cf. A. Ernout, 1961, p. 96.

${ }^{253}$ Chronologiquement et géographiquement (le mot est breton).

${ }^{254}$ A. J. Pfiffig, 1964, p. 50 : « Die spina ist nicht anderes als einer der Menhire der Megalithkultur $\gg$.

${ }^{255}$ Cf. J. W. Poultney, 1959, p. 324 ; A. L. Prosdocimi, 1978, p. 713.

256 Jusqu'à $4 \mathrm{~m}$ de hauteur pour un obélisque de San Giuliano : cf. S. Steingräber, 1997, p. 110.

${ }^{257}$ Cf. S. Steingräber, 1997, p. 113.

${ }^{258}$ Cf. G. Colonna, E. Colonna di Paolo, 1978, p. 238 sqq, E. Colonna di Paolo, 1978, p. 11 .

${ }^{259}$ Contre 1'《identità stele-iovile », cf. A. Franchi de Bellis, 1981, p. 38.

${ }^{260}$ Cf. A. L. Prosdocimi, 1989, p. 538. 
funéraire ${ }^{261}$ - une dédicace s'adressant directement à un Jupiter infernal - Iúveí Flagiuí ? Ou encore aux stèles élevées sur les sépultures grecques, qui marquaient « la frontière entre la vie et la mort $»^{262}$ ? A Gubbio, cette pierre fichée dans le sol qui s'élance vers le ciel est comme un lien entre le monde d'Hunte et celui de Iuuie, comme la manifestation symbolique de cette dualité divine qu'il est possible d'honorer conjointement par l'application d'un onguent.

Cette ambivalence s'avère cependant inégalitaire : comme il s'agit de l'Huntia et non d'une *Iuuia, le rituel privilégie l'aspect chthonien, ce qui supposerait que dans ces théonymes binaires associant deux divinités autonomes la première partie l'emporte : Hunte Iuuie est d'abord Hunte et l'épithète Iuuie dont il est paré le teinte d'une «touche» jovienne. A l'évidence, la lourde danse à trois temps (ahtrepuřatu) qu'exécute l'officiant ${ }^{263}$ s'adresse à Hunte : l'invocation divine (tiu puni tiu vinu) se fait en même temps que l'ařfertur frappe le sol, de son pas pesant et cadencé, loin de la spina trop liée à Iuuie, afin de mieux capter l'attention de ce dieu souterrain.

La cérémonie de l'Huntia est étroitement liée aussi à la lune, un astre ambivalent dans l'imaginaire antique. Sœur du soleil chez les Grecs ${ }^{264}$, «inventée par la nature comme remède aux ténèbres $»^{265}$, elle n'en a pas moins partie liée avec notre monde terrestre : «voisin[e] de la terre par sa composition comme par sa situation ${ }^{266}$, elle est appelée «par les uns 'l'astre terrestre', par d'autres 'la terre olympienne', par d'autres enfin 'le domaine de la déesse à la fois souterraine et céleste' $\gg{ }^{267}$. En raison de ses mouvements périodiques de croissance et de décroissance ${ }^{268}$, elle semble également « soumis[e] à la temporalité et à la mort » ${ }^{269}$. Elle préside ainsi « à ce qui, dans la vie, est cyclique »: naissance ${ }^{270}$, sénescence, mort des hommes comme des plantes. La pleine lune, plus encore, qui voit se dérouler l'Huntia, marque à la fois l'acmé de la lumière nocturne et les prémices de sa disparition, ce qui sied parfaitement aux traits ambivalents du dieu ombrien.

\section{1. 2. En Grèce}

${ }^{261}$ Cf. A. Franchi de Bellis, 1981, p. 43.

262 R. Sorel, 2005, p. 1020.

${ }^{263}$ Qui peut rappeler les «sauteries à trois temps » des Saliens (J. Bayet, 1971, p. 91), qui « sautaient et frappaient le sol de leurs pieds suivant un rythme ternaire » (R. Bloch, 1958, p. 709) dans le but « sans doute [...] d'écarter les mauvais esprits à l'entrée et à la fin de la saison guerrière » (G. Dumézil, 1987, p. 247, n. 1).

${ }^{264}$ Hésiode, Théogonie 371 ; Euripide, Les Phéniciennes 175.

265 Pline l'Ancien, II 6, 41.

${ }^{266}$ C. Préaux, 1973, p. 64. Cf. Pline L'Ancien, II 6, 46 : «les taches ne sont que des excrétions de la terre $»$.

267 Plutarque, De Defectu oraculorum, 416 A.

${ }^{268}$ Cf. Plutarque, De Defectu oraculorum, 416 A : " Quant à la ressemblance de l'être mixte des génies, elle nous est fournie exactement par la lune, dont le comportement s'accorde avec le leur, puisqu'elle offre aux yeux des déclins, des accroissements et des changements ». Cf. aussi Pline l'Ancien, II 6, 42: «toujours en train de croître et de décroître ».

${ }^{269}$ G. Durand, 1984, p. 111.

${ }^{270}$ Sur le lien entre la lune et la féminité, cf. G. Durand, 1984, p. 112. 
Autre bénéficiaire de sacrifices canins ${ }^{271}$, dans le monde grec cette fois, Hécate, qui est régulièrement associée aux chiens ${ }^{272}$ (fig. 12), présente le même aspect binaire qu'Hunte Iuuie. Liée également à la nuit et à la lune ${ }^{273}$, elle est indéniablement une divinité du sous-sol, parée des épiclèses Chthonia et Katachthonia ${ }^{274}$ mais aussi Melaina $^{275}$ (sombre, funeste) comme le sont les Erinyes. Pourtant, nombre de textes littéraires et épigraphiques insistent sur son caractère lumineux et sa dimension céleste $^{276}$ : souvent représentée chargée de flambeaux ${ }^{277}$, elle est qualifiée de Phosphoros chez Euripide ${ }^{278}$ et d'Ourania dans une inscription de Phrygie ${ }^{279}$. Hésiode fait de cette appartenance à tous les éléments une caractéristique de la déesse :

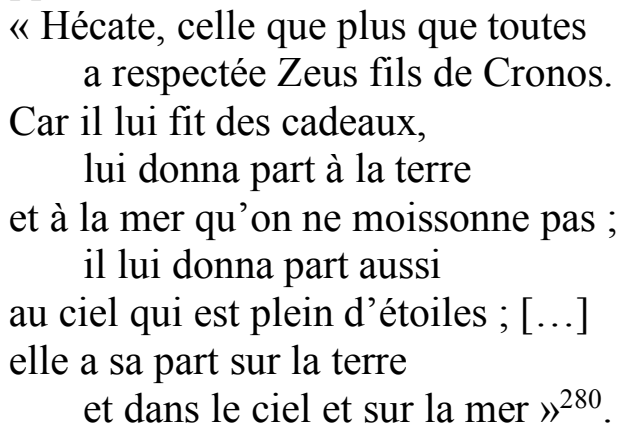

Virgile l'affirmait aussi : « Hécate [...] règne au ciel et sur l'Érèbe ${ }^{281}$. Un tel portrait rappelle de manière frappante le dieu ombrien. Désignée comme Angelos ${ }^{282}$, Hécate assure la transition entre le monde des morts et celui des vivants ${ }^{283}$, d'autant qu' elle est aussi perçue comme la protectrice des passages ${ }^{284}$, veillant sur les portes (Proturaia ${ }^{285}$ ),

${ }^{271}$ Aristophane, fr. 204 ; Plutarque, Questions Romaines 52 ; Lycophron, Alexandra 77-78.

${ }^{272}$ Cf. $L I M C, \mathrm{VI}^{2}$ « Hécate » $\mathrm{n}^{\circ} 95$ et 166.

273 Théocrite, Idylle II, 60.

${ }^{274}$ Schol. Teokr. 2, 12 ; REG, BullEpigr 1938, $\mathrm{n}^{\circ} 23$.

${ }^{275}$ Cf. une inscription phrygienne dans E. C. Haspels, 1971, p. $324 n^{\circ} 63$.

${ }^{276}$ Cf. D. Soren, 1998, p. 624.

$277 \mathrm{Cf}$. Hymne homérique à Déméter, 52 : «Hécate vint à sa rencontre tenant à la main une lampe »; 61: « et toujours elle tenait en main des torches enflammées ». Cf. aussi Sénèque, Médée 842.

${ }^{278}$ Euripide, Hel. 569.

${ }^{279}$ REG, BullEpigr 1971, $\mathrm{n}^{\circ} 654$.

${ }^{280}$ Hésiode, Théogonie 412-415, 429 (trad. J.-L. Backès).

${ }^{281}$ Virgile, Enéide II 247.

282 Sophron, $C G F$ p. 161.

${ }^{283}$ Cf. S. I. Johnston, 1990, p. 31.

284 Cf. Th. Kraus, 1960, p. 96 ; S. I. Johnston, 1990, p. 24 : «Whenever a soul is entering into partnership with a body - at birth or in childhood - [Hecate] [...] is at hand; where a soul is separating from a body, in burials of the dead, she is there ». Les repas d'Hécate sont d'ailleurs offerts aux carrefours chaque mois à la nouvelle lune (la nuit où la vieille lune s'achève et la nouvelle commence). Cf. aussi G. Dumézil, 2003, p. 603 qui rapproche Hécate de l'italique Féronia et du védique Rudra : " Ces divinités se tiennent sur le seuil qui sépare le sauvage et le familier, la brousse et la cité, ce qui n'est pas encore domestiqué et ce qui déjà obéit à l'homme. Elles ne président pas proprement aux commencements, elles ne sont pas proprement non plus d'un côté ou de l'autre de la frontière des deux domaines, mais elles aident l'homme à réussir à son 
les murailles (Epipurgidia ${ }^{286}$ ) et les carrefours ${ }^{287}$ mais aussi sur les naissances en tant que déesse des parturientes ${ }^{288}$. Régulièrement associée à Hécate, Enodie, qui reçoit des chiens à Colophon ${ }^{289}$, est elle aussi une divinité des passages.

Autre divinité qui patronne les enfantements, Ilithyie, très souvent accompagnée d'un chien $^{290}$ (fig. 13) et sans doute destinataire d'un sacrifice canin ${ }^{291}$, présente elle aussi une nature duelle : habitante de l'Olympe, elle est également la sœur de figures plus sombres - les Moires qui règnent sur les destinées.

La déesse Héra qui à Paestum semble associée au chien ${ }^{292}$ et même peut-être honorée dans son sanctuaire du Sele par des sacrifices canins, présente conjointement elle aussi des traits chthoniens ${ }^{293}$ et ouraniens; parfois qualifiée de Téleia (qui peut renvoyer à téleuté, la mort, la fin ${ }^{294}$ ), elle est invoquée aussi comme une divinité céleste : "divine Héra, nous te prions, levant au ciel nos mains tendues vers le rayonnement des astres, ton séjour $»^{295}$; elle était d'ailleurs considérée à l'origine de la Voie lactée. Mais elle est surtout une déesse «des limites du territoire et des zones de contact», dont les sanctuaires, comme celui du Sele, sont souvent extra-urbains, marquant ainsi «la maîtrise des cités sur les zones agricoles $»^{296}$. Cette caractéristique participe aussi à

profit le transfert du dangereux et de l'inexploité à l'usuel et l'utile ». Cf. aussi C. Orrieux, 1997.

${ }^{285}$ Aristophane, Vespae 800-804.

286 Pausanias 2, 30, 2.

287 Ovide, Fastes I, 141-142 : «Hécate, comme tu vois, peut tourner ses visages dans trois directions, afin d'assurer la surveillance des carrefours qui s'ouvrent sur trois routes $\gg$.

288 Cf. Horace, Odes III, 22-25 (qui rapproche Hécate et Diane) : « Gardienne des montagnes et des bois, vierge qui, trois fois invoquée, entends les jeunes femmes dans les douleurs de l'enfantement et les arraches à la mort, déesse à la triple forme [triformis] », cf. R. Sorel, 2005, p. 1019.

${ }^{289}$ Pausanias, III 14, 9.

${ }^{290}$ Cf. LIMC, IV 2 « Eileithyia » ${ }^{\circ} 58$.

${ }^{291}$ Si l'on considère qu'il y a eu erreur de lecture chez Plutarque, Questions Romaines 52 : cf. M. Nouilhan, J.- M. Pailler, P. Payen, 1999, p. 152.

${ }^{292}$ Sur un vase nuptial retrouvé à Paestum (cf. A. D. Trendall, $1987112 \mathrm{n}^{\circ} 148$; M. Cipriani, 1997 fig. 16) sont figurés Héra, Pâris, Hermès au centre et ... un chien (habituellement considéré comme le compagnon de Pâris mais qui pourrait l'être tout aussi bien d'Hermès que d'Héra). En revanche, une statue mise au jour à Paestum et habituellement interprétée comme une représentation d'Héra Hippia (cf. P. Zancani Montuoro, 1951; M. Cipriani, 1997 fig. 12) ne peut raisonnablement être comprise comme une Héra «au chien » en dépit de M. Sestieri Bertarelli, 1989, p. 27 selon laquelle il « è dubbio che possa trattarsi di un cavallino ».

${ }^{293}$ Cf. P. Zancani Montuoro, 1937, p. 305 qui invoque cet aspect (« ha gli attributi ad un tempo della divinità sotteranea ») pour expliquer le sacrifice canin. Cf. aussi M. Dewailly, 1997, p. 203 : « la déposition d'objets à l'intérieur de puits votifs reflète sans doute un des aspects du culte d'Héra à Foce del Sele, l'aspect chthonien "; P. Lévêque, 1997, p. 269 qui voit dans l'heraion du Sele un « sanctuaire extra-urbain, sans doute à valeur funéraire $»$.

${ }^{294}$ Cf. P. Levêque, 1997, p. 268, qui relie cette épiclèse aussi à télété (« initiation aux mystères, célébration de mystères $»)$.

295 Euripide, Hélène 1094-1095.

${ }^{296}$ A. Jacquemin, 2005, p. 1026. 
l'ambiguïté d'Héra: « déesse de l'intérieur et de l'extérieur [...]; elle répugne aux dépassements de limites $»^{297}$.

Aphrodite Ourania ${ }^{298}$ - la bénéficiaire des rituels canins accomplis sur l'agora d'Athènes - est elle aussi une divinité des transitions comme le souligne clairement l'attribut dont elle est régulièrement parée sur les représentations iconographiques $^{299}$ (fig. 14) : l'échelle, qui permet « la communication entre le ciel, où se déplace la déesse et la terre, sur laquelle son aura se répand $»^{300}$. Aphrodite Ourania réunit la terre et le ciel comme elle patronne les transitions de $1^{\text {'existence }}{ }^{301}$, en facilitant le passage de l'état virginal à la situation matrimoniale ${ }^{302}$. Dans le puits de l'agora, situé à un carrefour ${ }^{303}$ (fig. 15), la représentation de cette déesse sous la forme d'un pilier hermaïque ${ }^{304}$ (fig. 16) souligne avec encore plus d'insistance son aspect liminaire.

Les rituels canins accomplis à Sardes l'ont peut-être été en l'honneur de Kandaulas $^{305}$ qu'une glose byzantine ${ }^{306}$ présente comme l'« étrangleur de chiens ». La physionomie de ce dieu se laisse difficilement cerner, faute de sources. Cependant, le poète Hipponax le rapproche d'Hermès Kynanchès ${ }^{307}$, c'est-à-dire d'une divinité régulièrement associée au chien ${ }^{308}$ (fig. 17) et surtout liée une fois encore aux passages : le messager de Zeus est le dieu de la «médiation » ${ }^{309}$ par excellence, aidant au franchissement des frontières ${ }^{310}$ (qui permet ainsi à Héraclès d'attirer Cerbère hors des

${ }^{297}$ P. Lévêque, 1997, p. 267.

${ }^{298}$ Sur cette épithète très majoritairement dévolue à Aphrodite, $\mathrm{cf}$. V. Pirenne-Delforge, 2005.

${ }^{299}$ Cf. C. M. Edwards, 1984 ; LIMC II $^{2} 138$ n $^{\circ} 1406$.

${ }^{300}$ V. Pirenne-Delforge, 1994, p. 22.

${ }^{301}$ R. Rosenzweig, 1999, p. 122, 125 («the goddess of unity par excellence »).

${ }^{302}$ Cf. Euripide, Phaethon 227-228 « la céleste fille de Zeus, la souveraine des amours, elle qui mène les jeunes filles au mariage, Aphrodite $»$.

${ }^{303}$ Cf. T. L. Shear Jr, 1984, p. 4 fig. 3.

${ }^{304}$ Cf. T. L. Shear Jr, 1939, p. 239 fig. 37.

${ }^{305}$ Selon l'hypothèse séduisante de C. H. Greenewalt, 1978, p. 40-55 qui rejette comme destinataire de ces rites Enyalios qui aurait selon certains (J. G. Pedley, 1974, p. 99) été honoré par des «expatriés» de Carie en Lydie (Enyalios, en effet, recevait des sacrifices sanglants et non une offrande sous forme de déposition); la même remarque vaut pour Hécate qui, certes, se voyait offrir des dîners $(\delta \varepsilon \tilde{\imath} \pi v \alpha)$ mais déposés sur le sol et non pas enterrés.

306 Scholie de Johannes Tzetzes, Chiliades 1.144 (ed. Cramer, Anecdota Graeca) qui explique que Kandaulas signifie $\sigma \kappa \nu \lambda \lambda o \pi v \iota \kappa \tau \eta \varsigma$ (" étrangleur de jeunes chiens »).

307 Hipponax, 103-106 (édition O. Masson, 1962) : « [II] appela en criant le fils de Maia, le roi de Cyllène 'Hermès étrangleur de chiens', en méonien Kandaulas, compagnon des voleurs, combats ici avec moi ». Cf. C. Mainoldi, 1984, p. 76.

${ }^{308}$ Cf. LIMC, $\mathrm{V}^{2} 242, \mathrm{n}^{\circ} 497$ et $\mathrm{V}^{2} 246, \mathrm{n}^{\circ}$ 554a. Hermès était d'ailleurs assez souvent rapproché du dieu canidé Anubis (cf. LIMC $\mathrm{I}^{1}{ }^{863}$ ) au point que Plutarque (De Is. et Os. 375 e-f) et Porphyre (De imaginibus frg. 8) emploient le terme "Hermanubis » pour qualifier une divinité de l'Egypte romaine des IIIè-IIè s. et que l'iconographie représente habituellement accompagnée d'un chien (cf. LIMC $\mathrm{V}^{2} 189, \mathrm{n}^{\circ} 14$ ).

${ }^{309}$ Cf. L. Kahn, 1978, p. 165-186. Cf. aussi J.-P. Vernant, 1965, p. 158 : « Il est le lien, le médiateur entre les hommes et les dieux, ceux d'en bas comme ceux d'en haut ».

${ }^{310}$ Cf. L. Kahn, 1979. 
Enfers $^{311}$ : fig. 18); cet envoyé des Olympiens présente aussi, à en croire l'épiclèse Chthonios dont il est régulièrement paré ${ }^{312}$, un évident aspect infernal ${ }^{313}$.

\section{1. 3. En Étrurie}

En Étrurie, à Cortona, une semblable dichotomie apparaît dans l'association de deux divinités honorées par l'offrande, semble-t-il conjointe, de statuettes de chiens en bronze, d'époque hellénistique, qui portent comme inscription, pour l'une s(elans) calustla, pour l'autre tinscvil. Le premier théonyme - dont il s'agit, à cette date, de la seule attestation ${ }^{314}$ - a une forme binaire ${ }^{315}$ comme il est fréquent dans les mondes étrusque $^{316}$ et italique (ombrien en particulier). Ce dieu - « Selans de Calus » mot à mot - revêt à l'évidence un aspect funéraire, «infernal » ${ }^{317}$ puisque Calus est «identifiable comme le dieu de la mort $»^{318}$. A cette figure chthonienne - masculine comme le sont toutes les divinités étrusques du monde catachthonien ${ }^{319}$ - est associée une divinité terrestre : $\operatorname{Sel}(v) a n s^{320}$ a été classé par M. Pallottino ${ }^{321}$, dans la reconstruction qu'il a faite du ciel étrusque à partir du foie de Plaisance, parmi les divinités de la terre et de la nature, aux côtés de Fufluns qui «protège les champs » ${ }^{322}$; ce dieu s'avère assez proche, semble-t-il, du Siluanus romain, "patron de la siluatica pastio, du pâturage d'été dans la montagne boisée ${ }^{323}$; mais «sa fonction majeure est de veiller sur les limites, les confins, la frontière entre les lieux cultivés et les lieux incultes $»^{324}$. Le deuxième théonyme est d'interprétation plus simple : dieu du ciel par excellence, Tinia qui a souvent été rapproché du Jupiter romain ou du Iuuie ombrien, est une " divinité masculine liée au jour et à la lumière $»^{325}$. L'association à Cortona de Selans Calustla et de Tinia, c'est-à-dire d'une figure chthonienne et terrestre et d'une divinité céleste rappelle évidemment le visage ambivalent d'Hunte Iuvie tout comme la physionomie paradoxale d'Hécate.

${ }^{311}$ Cf. L. Chazalon, 1995 fig. 4 et LIMC, $\mathrm{V}^{2}$ « Heraklès » $\left.\mathrm{n}^{\circ} 2555\right)$.

${ }^{312}$ IG IX 2, 638 ; Eschyle, Choéphores I.

313 Cf. Raingeard, 1934, p. 571-572: Hermès est « chthonien et olympien »; il est «à mi-chemin entre les enfers et le ciel ».

${ }^{314}$ M. Pallotino, 1954, p. 642 ; F. Roncalli, 1985, p. 66.

315 Cf. C. de Simone, 1997, p. 192.

316 C. de Simone, 1997.

${ }^{317}$ C. de Simone, 1997, p. 187, 190.

318 M. Cristofani, 1997, p. 217.

${ }^{319}$ M. Cristofani, 1997, p. 217.

320 Selon H. Rix, 1981, Selans serait d'origine ombrienne, comme tous les dieux étrusques dont le nom porte le suffixe $-n s$; en raison de l'absence de ce dieu ou de tout équivalent dans les inscriptions ombriennes qui nous sont parvenues, sans doute faut-il être plus prudent, en estimant que Selans et Nethuns, "correspondent au Silvain et au Neptune latins, comme des noms d'origine italique, sans préciser davantage » (L. B. van der Meer, 1997, p. 223). Cf. aussi M. Torelli, 2000, p. 286.

${ }^{321}$ M. Pallottino, 1956.

${ }^{322}$ Cf. M. Cristofani, 1997, p. 217.

${ }^{323}$ G. Dumézil, 1987, p. 245. Horace, Ep. 2, 22 qualifie Siluanus de «tutor finium ».

${ }^{324}$ J.-R. Jannot, 1998, p. 169.

${ }^{325}$ Cf. M. Cristofani, 1997, p. 217. Tinia a aussi un caractère funéraire dans d'autres inscriptions : M. Pallotino, 1954, p. 270 (Tinia Calusna) ; cf. aussi LIMC, VI 400. 
La divinité majeure de Pyrgi, où ont été retrouvés des ossements canins dans un puits rituel, est $\mathrm{Uni}^{326}$ qui présente, elle aussi, des traits complexes : alors que les Puniques l'appelaient Astarté et les Grecs l'identifiaient à la duelle Ilithyie ${ }^{327}$ ou à Leucothea, les Romains l'ont rapprochée ${ }^{328}$ de leur ambivalente Mater Matuta ${ }^{329}$ - d'autant plus aisément que le sanctuaire élevé à l'origine, dans les années 510, en l'honneur de la seule $\mathrm{Uni}^{330}$ (le temple B) a ensuite, vers $460^{331}$, accueilli dans le temple A la divinité aurorale $T_{\text {Thesan }}^{332}$, la déesse « des origines, celle de la naissance du jour, mais aussi de toutes les naissances ${ }^{333}$. C'est justement à l'angle occidental de ce dernier lieu de culte, dans un puits rituel (fig. 19) ${ }^{334}$, que le squelette canin a été exhumé. Cette déesse avait aussi une dimension chthonienne évidente comme le souligne la présence entre les deux temples, d'un grand autel carré qui « était en réalité un bothros communicant par un canal vertical avec le monde chthonien $»^{335}$, comme il en existait à Santa Marinella, Orvieto et Bolsena ${ }^{336}$.

\section{1. 4. A Rome}

Les divinités romaines honorées par des sacrifices canins reflètent elles aussi une telle dualité : c'est le cas de Genita Mana, dont le nom même manifeste l'ambivalence. Divinité quasiment inconnue ${ }^{337}$, dont on ne connaît aucun temple, elle devait être honorée dans le cadre de rites familiaux. Plutarque propose lui-même ${ }^{338}$ des interprétations de ce théonyme : il relie d'abord genita à genesis (naissance) et traduit mana par "flux", ce qui ferait de cette déesse une protectrice du «flux de la naissance ", de la "génération en cours »; il rappelle aussi que mana est un adjectif appliqué traditionnellement aux dieux mânes et qu'il correspond également au grec phthartos («corruptible») - Genita Mana présidant alors à la «naissance des périssables ». A l'évidence, ce théonyme manifeste l'association paradoxale d'une

${ }^{326}$ Et qui jouissait aussi à Cortona (où ont été retrouvées les deux statuettes en bronze de chien) d'une grande importance : selon J.-R. Jannot, 1998, p. 166, « elle en était la divinité poliade, si l'on en croit une dédicace : mi unial curtum $=$ je suis à Uni de Cortone $»$.

${ }^{327}$ Cf. Strabon, V, 2, 8.

328 Cf. R. Bloch, 1968 ; G. Colonna, 1981 ; J. Champeaux, 1987, p. 313 ; J.-R. Jannot, 1998, p. 166.

${ }^{329}$ Cf. infra

${ }^{330}$ Cf. J. -R. Jannot, 1998, p. 123.

${ }^{331}$ Cf. J. -R. Jannot, 1998, p. 124.

${ }^{332}$ Cf. M. Cristofani, 1997, p. 216. R. Bloch, 1968, p. 373.

333 J.-R. Jannot, 1998, p. 168.

334 Cf. L. Caloi, M.-R. Palombo, 1980, p. 293.

335 J.-R. Jannot, 1998, p. 106.

${ }^{336}$ Dont plusieurs sont dédiés à Tinia qui lui aussi revêt des traits infernaux, cf. J.-R. Jannot, 1998, p. 112.

${ }^{337}$ Sur Genita Mana, cf. E. Samter, 1910 ; A. L. Prosdocimi, 1996, p. 602 qui, de façon trop restrictive, en fait une déesse du monde agraire, liée à Cérès, patronnant la maturation du grain.

${ }^{338}$ Plutarque, Questions Romaines 52. 
divinité de la naissance ${ }^{339}$ et de figures infernales. Genita Mana revêt ainsi les qualités de la déesse Hécate à laquelle Plutarque fait d'ailleurs explicitement allusion dans le même passage: elle est ouranienne - comme l'est la Deivai Genetai samnite d'Agnone $^{340}$-, déesse de la vie autant que de la mort, dernière fonction dans laquelle les commentateurs l'ont trop souvent cantonnée ${ }^{341}$ en la rapprochant des mânes ou de Mana, la Mère des Lares ${ }^{342}$.

Précisément, les dieux Lares sont eux aussi associés aux chiens : les Lares Praestites, notamment, sont représentés la tête couverte d'une peau de chien ${ }^{343}$ et accompagnés de cet animal (fig. 20) (344 $^{34}$ et, sans doute, les ossements canins retrouvés dans l'aire du sanctuaire de Vesta ${ }^{345}$ à Rome proviennent-ils de chiens sacrifiés à ces divinités dont F. Coarelli ${ }^{346}$ a localisé le lieu de culte ${ }^{347}$, à proximité du temple de la déesse, le long du vicus Vestae, à deux pas des murailles de la Cité (fig. 21). L'aspect chthonien et démoniaque des Lares a souvent été mis en avant par les commentateurs ${ }^{348}$, qui les ont rapprochés, dès l'époque d'Auguste, des di parentes, des mânes. Pourtant, comme J. Scheid l'a montré, si les Lares «sont honorés [...] comme les mânes, comme une divinité infernale, $[\ldots]$ ils ne sont pas des dieux infernaux ou funestes, tout au contraire, ils sont figurés avec une corne d'abondance [...] et reçoivent avec leur " mère ", des victimes au pelage clair $»^{349}$. Ce 《statut intermédiaire », ambigu, apparaît clairement dans le récit étiologique d'Ovide qui présente les Lares (et Lara) « en route pour le séjour des mânes sans y parvenir $»^{350}$. Les Lares sont avant tout des divinités des limites, "patronnes et protectrices des portions de terrain $»{ }^{351}$, qui veillent «sur les lieux « critiques », carrefours, frontières et seuils ou sur les limites entre le monde des morts et celui des vivants $»^{352}$. Il n'est ainsi pas surprenant que leur lieu de culte à Rome se trouve près de la porta Romanula, au pied du Palatin ${ }^{353}$.

La nature de Robigo qui occupe une place mineure dans le panthéon romain n'est pas dépourvue d'ambiguïté non plus. Le sexe même de cette divinité appelée tantôt Robigo $^{354}$, tantôt Robigus ${ }^{355}$ est incertain ${ }^{356}$, comme il l'est pour seulement quelques

${ }^{339}$ Cf. J. De Grossi Mazzorin, 2001, p. 79 (qui la réduit à un seul aspect : « dea italica che presiedeva al ciclo mestruale ed era collegata più in generale alla sfera della fertilità $»)$.

${ }^{340}$ Cf. A. L. Prosdocimi, 1996, p. 519.

341 Cf. G. Wissowa, 1912, p. 240 ; surtout E. Tabeling, 1932, p. 92-95 ; L. Delatte, 1937, p. 97 : « la déesse du monde inférieur »; R. Robert, 1993, p. 124 ; A. Carandini, 1997, p. 199.

${ }^{342}$ Cf. Macrobe, Sat. I, 7.

${ }^{343}$ Plutarque, Questions Romaines 51 décrit ces Lares revêtus de peaux de chiens.

${ }^{344}$ Sur un denier de L. Caesius (cf. M. Crawford, 1974, p. 298, 1).

${ }^{345}$ Cf. E. Gjerstad, 1960, p. 314.

${ }^{346}$ Cf. F. Coarelli, 1983, p. 266-271.

${ }^{347}$ Sur la base d'une inscription : CIL, VI, 30960.

${ }^{348}$ Cf. E. Tabeling, 1932, p. 1-9, 92-95 ; F. Coarelli, 1983, p. 270 sqq.

349 J. Scheid, 1990, p. 597.

${ }^{350}$ J. Scheid, 1990, p. 597.

351 J. Scheid, 1990, p. 596-597. Cf. Properce, III, 3, 10 : « Ennius qui chanta [...] les Lares chassant Hannibal du site de Rome $»$.

${ }^{352}$ R. Robert, 1993, p. 125-126.

${ }^{353}$ Cf. F. Coarelli, 1993, p. 176.

${ }^{354}$ Ovide, Fastes 918 ; Tertullien, De Spect. 5, 8 ; Lactance, Div. inst., 1, 20, 17 ;

Augustin, De Ciuitate Dei, 4, 21. 
dieux romains tel Siue deus siue dea. Cette divinité agraire, « aux contours fuyants » ${ }^{357}$ est 1 ' « une des rares puissances mauvaises qui reçoivent un culte ${ }^{358}$. Ovide comme Columelle insistent sur la nocivité de cette mala ${ }^{359}$ et aspera Robigo ${ }^{360}$ aux mains scabrae ${ }^{361}$, dont la force puissante (uis tua non leuis est ${ }^{362}$ ) est mise au service de la destruction $^{363}$. Cette divinité possède en effet le pouvoir, par sa simple présence, d'interrompre la germination. Aussi, ce n'est pas son intervention qui est appelée comme il est d'usage dans les prières, mais son retrait et son absence ${ }^{364}$ : « Rugueuse Robigo, épargne les plantes de Cérès [...], écarte tes mains râpeuses des moissons [...], efface-toi, pour que le laboureur puisse toujours s'acquitter de ses vœux envers toi ». L'action de la déesse Robigo concerne un moment de transition majeure : celui de la renaissance de la végétation, de la réapparition de la vie depuis les profondeurs du sous$\mathrm{sol}^{365}$. Comme Genita Mana, elle représente pour les Romains à la fois l'espoir de la fécondité et la menace de la mort.

Mater Matuta, honorée tant à Rome qu'à Satricum par des sacrifices canins apparaît comme une autre divinité des seuils. Déesse de la lumière du matin ${ }^{366}$ et des naissances $^{367}$, comme la déesse védique Aurore, dont l'a rapprochée G. Dumézil, elle "chasse l'uniformité noire », repousse les ténèbres ${ }^{368}$ : des statuettes en bronze de

${ }^{355}$ Aulu-Gelle, 5, 12, 14 ; Varron, RR, 1, 1, 6 ; P. Festus, p. 325 L ; Servius, Ad Georg. $1,151$.

356 Si cette « ambiguité dans la définition du sexe » est banale chez les Etrusques (cf. M. Cristofani, 1997, p. 209), elle est beaucoup plus rare chez les Romains.

${ }^{357}$ A. Gianferrari, 1995, p. 129.

${ }^{358}$ G. Dumézil, 1987, p. 169.

${ }^{359}$ Columelle, De l'Agriculture, X, 342.

360 Ovide, Fastes 911.

361 Ovide, Fastes 921.

362 Ovide, Fastes 915.

${ }^{363}$ Ce que suggère son association avec le dieu de la guerre : Numa Pompilius, selon Tertullien, De Spectaculis, V, aurait institué des jeux en l'honneur de Robigo et de Mars (cf. C. Santini, 1991, p. 171).

${ }^{364}$ Ce qui fait dire exagérément à C. Santini, 1991170 que « non siamo in presenza di una vera divinità $»$.

${ }^{365}$ Cf. J.-N. Robert, 1985, p. 289-290 qui évoque le « lien symbolique qui unit le monde des morts à celui de la terre porteuse de fruits » dans l'imaginaire des Romains. L'augurium canarium se déroule lui aussi à un moment critique de "la vie des céréales » (cf. H. Le Bonniec, 1958, p. 123-124; A. L. Prosdocimi, 1996, p. 601) : «quand se forme l'épi dans sa gaine » (Pline l'Ancien, XVIII, 14 : Ita enim est in Commentariis Pontificum : augurio canario agendo dies constituantur, priusquam frumenta uaginis exeant, nec antequam in uaginas perueniant, c'est-à-dire exactement « avant que les grains de blé sortissent de leur enveloppe, mais non pas avant qu'ils ne s'y formassent » selon la traduction de G. Dumézil, 1987, p. 585), ce qui permet, selon A. L. Prosdocimi, 1996, p. 599-601, d'expliquer ce rite : le sacrifice d'un chien rend possible l'«augmentation », la "croissance » (idée contenue dans le terme augurium) de cet épi.

366 Cf. Lucrèce, V, 656 ; Priscien, II, 53.

${ }^{367}$ F. Coarelli, 1983, p. 247, pour qui cette déesse aurait été introduite à Rome depuis Satricum.

${ }^{368}$ G. Dumézil, 1987, p. 67. Cf. aussi J. Heurgon, 1970, p. 360 ; J. Champeaux, 1987, p. 308-313; LIMC, $\mathrm{VI}^{1} 379$. 
Satricum la représentent ainsi la tête couronnée d'un disque figurant le soleil ${ }^{369}$ (fig. 22). Comme Robigo aussi, elle veille aux transitions, en patronnant les commencements ${ }^{370}$ - des jours, et partant, des vies humaines ${ }^{371}$ : elle est d'ailleurs célébrée par la fête des Matralia du 11 juin, peu avant le solstice d'été car en ces temps « où les jours, comme fatigués, réduisent à presque rien leur croissance pour bientôt se mettre à décroître $\aleph^{372}$, l'intervention de la déesse va devenir, plus que jamais, indispensable.

Dieu des limites enfin, de celles qui « séparent la civilisation de la sauvagerie ${ }^{373}$, apparaît Faunus à qui est destiné le chien sacrifié au cours des Lupercales ${ }^{374}$, comme l'assure Plutarque : «le sacrifice est fait en l'honneur de Pan [=Faunus]; or, le chien est cher à Pan à cause des troupeaux de chèvres ${ }^{375}$. La cérémonie des Lupercales ${ }^{376}$, durant laquelle s'affrontent dans une course effrénée deux groupes de Luperques - les Luperci Fabii et les Luperci Quintilii ${ }^{377}$ - vêtus de peaux de chèvre et qui s'achève par un sacrifice canin, révèle, dans son déroulement et ses intervenants, un double balancement : d'une part entre le monde sauvage ${ }^{378}$ et le monde civilisé, les Luperques figurant les «peuples sauvages » non encore policés; d'autre part, entre le monde chthonien et les espaces joviens, alternance très proche de celle qui sous-tend à Gubbio le rituel de l'Huntia. Cette fête revêt en effet d'indéniables aspects chthoniens: célébrée le 15 février, pendant les Parentalia qui sont consacrées au culte privé des morts $^{379}$, elle honore Faunus qui est appelé «infernus deus » par Servius ${ }^{380}$ et qui s'est vu élever un temple sur l'île tibérine, dans le voisinage de l'infernal Veiovis ${ }^{381 .}$ Toutefois, des éléments joviens ${ }^{382}$ peuvent être détectés dans ce rite : en premier lieu la

${ }^{369}$ Cf. $L I M C$, VI 193 fig. 1 et 2.

${ }^{370}$ F. Coarelli, 1983, p. 325.

${ }^{371}$ Cf. G. Dumézil, 1987, p. 344 : « accueillant le Soleil naissant, elle pouvait être

naturellement priée pour assurer d'heureuses naissances ».

372 G. Dumézil, 1987, p. 344.

${ }^{373}$ R. Robert, 1993, p. 127 ; cf. aussi G. Dumézil, 1987, p. 350.

${ }^{374}$ Sur cette cérémonie, cf. Ovide, Fastes II, 267-474 ; Plutarque, Questions Romaines 21, 57.

375 Plutarque, Questions Romaines 68 (280 c).

376 Qui met sans doute en scène la fondation de la Cité, cf. B. Liou-Gille, 1980, p. 180194.

${ }^{377}$ Les Luperci Fabii représentant Rémus, les Luperci Quintilii Romulus (cf. Ovide, Fastes, II 377-378).

${ }^{378}$ Cette fête est sans doute étymologiquement liée au loup, cf. G. Dumézil, 1987,

p. 352. Aussi A. Pigagniol, 1923, p. 103.

${ }^{379}$ Cf. G. Dumézil, 1987, p. 371-372.

${ }^{380}$ Servius, Ad Aen., 7, 91.

381 Macrobe, Saturn. III, 9, 10 ; Denys d'Halicarnasse, II, 10, 3 ; cf. G. Piccaluga, 1963.

${ }^{382}$ M. Corsano, 1977, p. 146-150 rattache aussi l'équipe des Quinctiales qui est opposée à celle des Fabiani au dieu céleste, en rappelant que de nombreux représentants de la gens Quinctii ont pris le cognomen «Capitolinus » et manifesté une grande ferveur à l'égard du dieu capitolin : par exemple, en 380 av. J .-C., Titus Quinctius Cincinnatus Capitolinus après sa victoire sur les Etrusques de Préneste emporta au temple capitolin la statue de Jupiter Imperator qui se trouvait dans le temple de Fortune (Tite-Live, VI, 29, 8-10) ; en 197 av. J.-C., Titus Quinctius Flamininus, éleva au Capitole une statue de Zeus Ourios de provenance macédonienne (Cicéron, Verr. IV, 57-58, 128-129). Pour 
présence, affirmée par Ovide ${ }^{383}$, du flamen dialis - véritable « image de Jupiter $»^{384}$ - qui doit pourtant en règle générale se garder de tout contact avec les bûchers funèbres et les cadavres $^{385}$ mais aussi avec les chiens avec lesquels il lui est interdit de cohabiter ${ }^{386}$. Au cours des Lupercales comme au cours de l'Huntia, sphères souterraines (Faunus, Hunte) et monde céleste (Jupiter, Iuuie) se côtoient.

Devant une association aussi fréquente des sacrifices canins et de divinités aussi particulières que Faunus, Mater Matuta, Robigo, Genita Mana ou les Lares, on peut légitimement penser que les rituels accomplis dans le cimetière de Poggio Gramignano l'ont été à destination d'une divinité aux caractéristiques proches, dans laquelle certains ont cru reconnaître Hécate ${ }^{387}$.

Ainsi, les figures divines honorées par des rituels canins possèdent, dans les communautés grecques, italiques, étrusques et romaines, des caractéristiques proches : divinités des confins et des transitions, à la personnalité contradictoire, elles se tiennent au seuil de la vie et de la mort, des domaines chthoniens et ouraniens, de la sauvagerie et de la civilisation.

Pourquoi de telles divinités, très rarement mentionnées en d'autres contextes, se voitelles honorées par le sacrifice d'un chien ? Ce n'est évidemment pas un hasard si des figures aussi particulières reçoivent en offrande une victime aussi peu fréquente. Une règle rituelle romaine, rappelée par Servius, veut d'ailleurs que chaque divinité soit honorée par une offrande appropriée, qui lui correspond - soit par similitude, soit par antinomie: uictimae numinibus aut per similitudinem aut per contrarietatem immolantur $^{388}$. C'est par exemple au nom de cette coutume que sont généralement immolées aux dieux chthoniens des victimes noires, aux ouraniens des claires, aux déesses des victimes femelles et aux dieux des mâles : ainsi Latone ${ }^{389}$ comme Junon Reine reçoivent des vaches ${ }^{390}$ et Jupiter des boeufs ${ }^{391}$. Des usages semblables s'observent à Gubbio où les divinités sont honorées par des victimes de leur sexe (le dieu Serfe ${ }^{392}$ reçoit l'offrande de trois porcs, la déesse Prestota ${ }^{393}$ celle de trois truies $^{394}$ ) et d'une couleur qui leur agrée (à Prestate reviennent des animaux

autant aucune source antique ne relie cette famille explicitement à Jupiter et les actes rapportés peuvent rappeler les gestes habituels des imperatores.

383 Ovide, Fastes II, 282.

384 Plutarque, Questions Romaines 3.

${ }^{385} \mathrm{Cf}$. Aulu-Gelle, X, 15.

386 Plutarque, Questions Romaines 111 : «Il n'est donc pas anormal que ceux qui ont été choisis pour servir le dieu le plus haut et le plus pur se voient interdire de faire du chien leur familier et leur compagnon $»$.

387 Cf. D. Soren, 1998.

${ }^{388}$ Servius, Ad Verg. Georg., II, 380.

389 Tite-Live, XXV, 12, 13.

390 Tite-Live, XXVII, 37, 11.

391 Tite-Live, XXVIII, 38, 8.

392 TE Ib 24.

393 TE Ib 27.

394 Cf. G. Devoto, 1967242. 
sombres $^{395}$; à Vufiune des boeufs blancs ${ }^{396}$ ); il serait donc fort surprenant qu'il n'y ait aucune correspondance entre l'unique victime sacrificielle et l'unique dieu de l'Huntia.

Dans les pratiques rituelles des Grecs comme des habitants de l'Italie péninsulaire, il $\mathrm{y}$ a, à n'en pas douter, un lien intrinsèque entre le chien et la nature - à la fois double et liminaire - des dieux auxquels il est offert.

\section{2. ... à l'ambivalence des chiens}

\section{2. 1. Terrifiants et affectueux}

L'image du chien dans l'Antiquité est, elle aussi, ambivalente ${ }^{397}$ : il est décrit tantôt comme une bête féroce, porteuse d'impureté, au point d'être chassé de certains lieux de culte $^{398}$, tantôt comme l'animal le plus domestiqué ${ }^{399}$, symbole de la civilisation, paré de qualités humaines comme la fidélité 400 et l'affection ${ }^{401}$. Une telle ambiguïté est décelable chez Cerbère lui-même. Terrifiant monstre des Enfers ${ }^{402}$, il devient auprès

395 TE VIb 6 : «A Rubine sacrifie trois truies, rouges ou noires, pour Prestote Serfie Serfer Martier $»$.

$396 \mathrm{TE} \mathrm{Vb} 19$.

${ }^{397}$ Cf. D. Soren, 1998 , p. 625 : « dogs were believed to have a dual personnality in Antiquity ».

${ }^{398}$ Cf. Plutarque, Questions Romaines 111 : « les chiens ne sont admis ni à l'Acropole d'Athènes ni sur l'île de Délos [...] du fait de [leur] nature belliqueuse. [...] Par ailleurs, les Anciens ne jugeaient pas cet animal totalement pur; en effet, [...] il n'est consacré à aucun des dieux de l'Olympe »; Questions Romaines, 90 : «pour quelle raison, au moment du sacrifice à Héraklès, ne prononcent-ils le nom d'aucune autre divinité, et pourquoi un chien ne paraît-il jamais à l'intérieur de l'enclos [...] ? ». Cf. aussi Strabon, $\mathrm{X}, 5,5$ : «Rhénée est une petite île déserte à quatre stades de Délos, où les Déliens ont leurs tombeaux. En effet, il n'est pas permis d'ensevelir ni de brûler de cadavres à Délos même et il n'est pas non plus permis d'élever des chiens à Délos "».

399 Platon, Sophiste 231a : "Il est vrai que le loup ressemble au chien, mais l'un est l'animal le plus sauvage, l'autre le plus domestique ».

${ }^{400} \mathrm{Cf}$. le chien d'Ulysse, Argos, qui reconnut son maître après vingt ans d'absence (Odyssée, XVII, 292-322) ; cf. aussi « le chien de Xanthippe, père de Périclès, qui, ne pouvant se résigner à être abandonné par lui, sauta dans la mer et, nageant à côté de sa trière, aborda à Salamine, où, à bout de forces, il mourut en arrivant " (Plutarque, Thémistocle 10,10).

${ }^{401}$ Cf. Aristote, Histoire des animaux I, 1, 488 b, 6-7 : « (certains animaux) ont du coeur, sont affectueux et caressants comme le chien »; Elien, La Personnalité des animaux VII, 40 : «Voici encore des exemples qui illustrent l'affection hors pair et insurpassable dont savent témoigner les chiens. Quand le tragédien Pôlos mourut et qu'on le fit brûler, le chien qu'il avait élevé se fit incinérer avec lui en sautant dans le bûcher. Quand on fit brûler Mentor, ses chiens érythréens choisirent volontairement de partager sa fin et se firent incinérer avec lui. Alors que ses parents couchaient Théodore un brillant harpiste, dans son cercueil, son petit chien de Méléda se jeta dans la bière du mort et se fit enterrer avec lui ». Pline l'Ancien VIII, 61 qualifie le chien de fidelissimum

402 Sénèque, Hercule Furieux 782-791 : «Alors apparaît le palais de l'avide Pluton; c'est là qu'épouvante les ombres le cruel chien du Styx qui, en agitant sa triple tête avec 
d'Héraklès qui parvient à l'apprivoiser un animal obéissant et presque affectueux ${ }^{403}$ (fig. 18) : «Dès que le fils de Jupiter fut plus proche, le chien indécis s'assit dans l'antre, non sans une légère frayeur. [...] A ce moment, flattant de la main les affreux cous du monstre, Alcide les enchaîne de liens indestructibles et, oubliant sa propre nature, le chien, gardien toujours éveillé du royaume ténébreux, baisse craintivement les oreilles ; se laissant emmener et reconnaissant son maître, il le suit, la tête basse, en se battant les flancs de sa queue de serpents ${ }^{404}$. Comme l'a démontré C. Mainoldi, « le chien se trouve, en effet, toujours en équilibre entre une alliance totale avec l'homme, dans le respect des lois de la domestication, et un refus de ces normes civilisatrices $\gg{ }^{405}$.

\section{2. 2. Chthoniens et célestes}

A mi-chemin entre les terres civilisées et le monde sauvage, le chien est en outre associé tantôt au monde chthonien tantôt à l'ouranien.

Son appartenance au domaine du sous-sol ${ }^{406}$ et de la mort est quasi systématique dans ces communautés ${ }^{407}$ : en Grèce comme à Rome, Cerbère, on l'a vu, garde les Enfers $^{408}$. De même, chez les Etrusques, le dieu de la mort, Aita, qui est figuré dans les tombes de l'Ogre II à Tarquinia (fig. 23) et Golini I à Orvieto, comme sur un sarcophage de Torre San Severo (fig. 24) et sur un vase de Volterra, a la physionomie d'un homme barbu tenant un sceptre sur lequel s'enroule un serpent, et dont la tête est recouverte d'une peau de loup ou de chien-loup ${ }^{409}$.

A l'inverse, le chien a aussi partie liée avec les espaces célestes, joviens pourrait-on dire. En effet, les Grecs comme les Romains - et sans doute bon nombre d'autres peuples de la péninsule - ont donné le nom de cet animal à une constellation ${ }^{410}$; dans son explication des Robigalia, le flamine questionné par Ovide souligne d'ailleurs explicitement le lien entre la victime canine et cette région du ciel : « il existe un Chien, dit d'Icare, qui est une constellation : à son lever, la terre, brûlée, a soif et la moisson subit une maturation précipitée. Au lieu du chien astral on place ce chien sur l'autel, et il

un immense fracas, garde le domaine royal. Il a la tête toute souillée d'une bave que lèchent des couleuvres; sa crinière est hérissée de vipères et sa croupe tortueuse est un long dragon qui siffle. Sa fureur est digne de son aspect. Dès qu'il a entendu le bruit des pas, il rebrousse ses poils hérissés de reptiles qui s'y tordent et essaie de saisir le son en dressant l'oreille, car il est habitué à ouïr même les ombres ».

${ }^{403}$ Cf. L. Chazalon, 1995 fig. 4 ; LIMC, $\mathrm{V}^{2}$ « Herakles », $\mathrm{n}^{\circ} 2555$.

${ }^{404}$ Sénèque, Hercule Furieux 791-793, 807-812.

405 C. Mainoldi, 1984, p. 143.

${ }^{406}$ Cf. D. Soren, 1998, 620 ; J. De Grossi Mazzorin, 200180.

407 Comme dans d'autres: comme l'a remarqué G. Durand, 198492 : le chien est «symbole du trépas. En témoigne le panthéon égyptien si riche en figures cynomorphes : Anubis, le grand dieu psychopompe, est appelé Impou, " celui qui a la forme d'un chien sauvage », et à Cynopolis est vénéré comme dieu des enfers ».

${ }^{408}$ Sur les caractères infernaux du chien à Rome, cf : Virgile, Aen. VI, 257 ; IV, 608 ; Tibulle, I, 2, 52 (« les chiens farouches d'Hécate »); Ovide, Métamorphoses XV, 797 ; Horace, Sat. I, 8, 35 (infernas canes) ; Lucain, VI, 733 ; Servius, Ad Aen. VI, 257.

${ }^{409}$ Cf. E. Simon, 1997, p. 451 ; J.-R. Jannot, 1998, p. 82 ; G. Sena Chiesa, 1981, p. 203, tab. LIV.

${ }^{410}$ Par exemple Homère, Iliade 22, 29 ; Hésiode, Les Travaux et les Jours 417 ;

Sophocle, fragment 941. 
n'est mis à mort qu'en raison de son nom $»^{411}$. Le lien du chien avec Jupiter est d'ailleurs manifeste à Rome où il a pour charge de garder le temple du Capitole ${ }^{412}$ et c'est encore cet aspect jovien qu'il revêt dans le rite des Lupercales au cours duquel la mise à mort de « l'ennemi des loups » est « une punition que les représentants d'un monde chaotique et souterrain infligent au gardien céleste de l'ordre de Jupiter $»^{413}$ : la mort du chien annonce le triomphe paradoxal et provisoire du monde faunique sur le monde jovien. En cela le rituel initiatique et intégrateur ${ }^{414}$ accompli par les éphèbes de Sparte revêt une signification assez proche : après s'être affrontés d'une manière mi-hoplitique, misauvage, ils offrent à « Ényalios, dieu de la mêlée sauvage, deux chiens, c'est-à-dire le plus domestiqué des animaux $»^{415}$.

Par sa nature ambiguë qui répond à celle de tous les dieux auxquels on le sacrifie ${ }^{416}$, le chien apparaît comme l'animal le plus approprié pour remplir la fonction de « médiateur » entre deux mondes.

\section{2. 3. Gardiens des limites}

D'ailleurs, de tous les animaux, le chien paraît être dans l'imaginaire de ces peuples le mieux à même de marquer religieusement l'idée de séparation ${ }^{417}$, pour signifier, faire vivre et respecter les limites.

Telle est la fonction de Cerbère, aux portes des Enfers, comme le décrit Hésiode : « Là plus loin, la demeure retentissante du dieu des Enfers, [le puissant Hadès, et de la terrible Perséphone] s'élève. Un chien effrayant surveille le devant, impitoyable, il possède un art mauvais. Ceux qui arrivent il les flatte en même temps avec la queue et les deux oreilles, mais il ne les laisse plus ressortir; aux aguets, il dévore tout individu qu'il surprend sortant des portes ${ }^{418}$; c'est cette fonction que figure le plus souvent la céramique attique en le plaçant à côté d'une colonne qui symbolise le seuil des Enfers ${ }^{419}$ (fig. 25) et en présence d'Hermès, le dieu des passages ${ }^{420}$ (fig. 18).

411 Ovide, Fastes IV 938-942.

${ }^{412}$ Cf. Pline l'Ancien, N. H., XVIII, 284 ; XXIX, 57 ; Tite-Live, III, 29, 9 : « Des loups se montrèrent, dit-on, au Capitole et en furent chassés par des chiens ; ce prodige obligea à purifier le Capitole ». Cf. Cicéron, Pro Roscio, 20. Cf. Aulu-Gelle, 6, 1, 6 : " ce Scipion l'Africain avait l'habitude de venir au Capitole à la fin de la nuit avant le petit jour, de faire ouvrir le sanctuaire de Jupiter, là de s'attarder longtemps seul, comme s'il délibérait sur l'Etat avec Jupiter, et les gardiens du temple s'étaient étonnés souvent que, quand il arrivait seul au Capitole à ce moment-là, les chiens qui se déchaînaient toujours contre les autres n'aboyaient pas contre lui et ne l'attaquaient pas ». Dans le monde grec, au sanctuaire de Zeus à Olympie, Lucien, Tim. 4 mentionne aussi la présence de chiens.

${ }^{413}$ M. Corsano, 1977, p. 152.

${ }^{414}$ Cf. R. Robert, 1993134.

415 P. Vidal-Naquet, 1991, p. 204.

416 A Gubbio le dieu Hunte Çefi - uniquement chthonien - ne reçoit pas un chien comme victime sacrificielle mais trois bovins (vitlup) (Ib 4 / VI b 45).

417 Il appartient à ce que G. Durand (1984 69) appelle le "régime diurne » qui « se définit [...] d'une façon générale comme le régime de l'antithèse » (entre le pur et le souillé, le clair et le sombre, le haut et le bas, ...).

${ }^{418}$ Hésiode, Théogonie 767-773. Cf. aussi Sophocle, Edipe à Colone 1568-1578.

${ }^{419}$ Cf. F. Roncalli, 1997, p. 51.

${ }^{420}$ Cf. L. Chazalon, 1995 ; LIMC, $\mathrm{V}^{2} \ll$ Herakles » $\mathrm{n}^{\circ} 2555$. 
Tel est clairement aussi son rôle auprès des Lares Praestites qu'il accompagne dans l'iconographie monétaire ${ }^{421}$ (fig. 20) comme dans la statuaire : "Les Calendes de mai ont vu élever en l'honneur des Lares tutélaires un autel et des statuettes de ces dieux [...]. La raison du qualificatif qui leur a été accolé est que par leur surveillance ils assurent la sécurité de toutes choses. De plus, ils se tiennent prêts pour nous défendre et président à la protection des remparts de la Ville ; ils manifestent toujours leur présence et nous apportent leur aide. J'ajoute qu'un chien, fait de la même pierre, se tenait à leurs pieds : pour quelle raison se tenait-il en compagnie du Lare ? Tous deux protègent la maison et tous deux sont fidèles à leur maître. Les carrefours plaisent au dieu, les carrefours plaisent au chien. Le Lare comme la meute de Diane font fuir les voleurs. Vigilants sont les Lares, vigilants sont les chiens ${ }^{422}$. L'association des chiens et d'Hermès répond vraisemblablement au même schéma analogique : celui que les sources grecques décrivent comme le plus grand «ami des hommes ${ }^{423}$, qui aime « entre tous [leur] servir de compagnon $»^{424}$, qui se tient « à la porte $»^{425}$, « guettant dans la nuit $»^{426}$ n'est pas le chien mais Hermès.

C'est sans doute également «par la volonté de protéger une communauté qui se sentait menacée ${ }^{427}$ par un environnement hostile que des chiens ont été enterrés au pied des murailles de Paestum ${ }^{428}$ comme d'Ariminum (à proximité d'une tour défensive : fig. 26) ${ }^{429}$, mais aussi à Rome à la porta Mugonia ${ }^{430}$.

${ }^{421}$ M. Crawford, 1974, p. 298, tab. 40.

422 Ovide, Fastes V 129-130, 133-142 ; cf. aussi P. Festus, p. 250 L. : Praestitem in eadem significatione dicebant antiqui qua nunc dicimus antistitem.

${ }^{423}$ Aristophane, La Paix 392.

${ }^{424}$ Homère, Iliade, XXIV 334-335.

${ }^{425}$ Hymne homérique à Hermès, 14-15.

${ }^{426}$ Hymne homérique à Hermès, 146-147. Cf. J.-P. Vernant, 1965, p. 157.

${ }^{427}$ R. Robert, 1993, p. 123, qui donne aussi (135) au rituel romain de crucifixion canine (cf. Pline, $N$. H. 29, 57) une interprétation voisine, « il est $[\ldots]$ probable que Pline garde ici le souvenir d'un rite apotropaïque de protection du territoire »; le parcours suivi entre le temple de Iuuentas et celui de Summanus, au pied de l'Aventin «correspond aux abords de la Roma Quadrata et fait face au Lupercal [...] donc [aux] limites topographiques de la Rome primitive auxquelles se rapportaient déjà le culte des Lares Praestites et le sacrifice des Lupercalia ».

${ }^{428}$ Cf. R. Robert, 1993.

${ }^{429}$ G. Giusberti, 1990, p. 123 et J. Ortalli, 1990, p. 111 préfèrent y voir un rite de fondation en raison de sa localisation et de la présence conjointe de pièces de monnaie : « si tratta di un donarium offerto agli dei al momento stesso della costruzione delle mura, deposto e sepellito in un punto angolare, nodale per l'opera difensiva, a consacrarne l'edificazione e a suggellare l'inviolabilità e la sacralità del limite urbano ». Avec raison, R. Robert, 1993, p. 123 est plus prudent, rappelant que nous n'avons aucun témoignage littéraire de rituels sacrificiels de fondation ; il préfère y voir la volonté d'une communauté de concrétiser "par un acte religieux sa constitution en groupe unitaire par opposition à un espace extérieur ou à un corps étranger ».

430 Cf. A. Carandini, 1997, p. 199. Il paraît en revanche plus difficile d'accepter l'interprétation rituelle que M. Osanna, 2004, p. 55 fait du squelette canin presque complet retrouvé à côté d'une canalisation à Torre di Satriano : " potrebbe trattarsi delle tracce di azioni rituali effetuate in connessione con la «chiusura » stessa del sacro deposito, intervenuta in connessioni con trasformazioni sostanziali dell'area sacra »; cf. aussi M. Osanna, T. Giammatteo, 2001, p. 108. Ce squelette repose en effet à même le 
$\mathrm{Au}$ cours des Lupercales, comme l'a souligné R. Robert ${ }^{431}$, le chien a aussi pour fonction de «marquer une limite entre deux mondes ou entre deux phases chronologiques, entre l'avant et l'après, entre la cité constituée à l'intérieur de son enceinte et le monde extérieur et sauvage »; il « intervient pour [...] sceller le passage du monde primitif à celui de la cité ».

Les Robigalia au cours desquelles est sacrifiée une chienne se déroulent, selon le calendrier de Préneste au Vème milliaire de la uia Claudia $^{432}$, c'est-à-dire là encore en une zone de frontière, à la limite de l'Urbs et de l'ager.

Dans le sanctuaire d'Héra près de l'embouchure du Sele, les ossements canins ${ }^{433}$ retrouvés dans la partie supérieure du puits ${ }^{434}$ (fig. 27, 28), entre des blocs de calcaire qui en protégeaient le contenu, avaient sans doute pour fonction de marquer une séparation entre le monde terrestre, des vivants et celui du sous-sol, des morts. C'est peut-être ainsi qu'il conviendrait d'expliquer la présence du chien dans le puits de Pyrgi. Ces cavités qui plongeaient dans les entrailles du sous-sol créaient une communication avec un monde chthonien inquiétant. C'est ce que manifeste une série d'urnes étrusques des musées de Pérouse, Volterra, Florence et Chiusi ${ }^{435}$ qui mettent en scène un animal terrifiant surgissant d'un puits - à l'évidence une porte des Enfers ${ }^{436}$ afin d'emporter un mortel. Ce monstre parfois mi-homme mi-animal, plus souvent entièrement bestial, a les traits d'un canidé ${ }^{437}$, tantôt un loup tantôt un chien ${ }^{438}$. Ainsi,

sol, ne témoignant aucunement d'un enterrement organisé (par la cité, une confraternité, etc.) comme à Paestum et Ariminum : ne s'agit-il pas plutôt d'un chien venu mourir ici par hasard?

${ }^{431}$ R. Robert, 1993, p. 127 ; cf. aussi G. Dumézil, 1987, p. 350.

${ }^{432}$ Sur la petite divergence de lieu entre Ovide et le calendrier de Préneste, cf. C. Santini 1991, p. 174.

433 « Di età avanzata »: P. Zancani Montuoro, 1937, p. 303.

${ }^{434}$ Situé à $15 \mathrm{~m}$ au sud de l'angle sud-ouest du temple, profond de 3,52 m, ce bothros a été creusé au IVè s. av. J.-C. et utilisé pendant cent ou cent cinquante ans (cf. P. Zancani Montuoro, 1937, p. 300, fig. 68 ; P. Zancani Montuoro, U. Zanotti Bianco, 1951, p. 46). Il est fermé par un grand bloc de calcaire. Une première couche d'argile a révélé quelques restes de combustion et une lampe en terre cuite d'époque romaine; apparaissent ensuite deux autres blocs au milieu desquels trois lampes et deux monnaies impériales (du temps d'Hadrien), puis dans une couche de sable et d'argile les ossements de chien. Enfin, dans une strate sableuse, un autre bloc masquait une accumulation de récipients en céramique (amphores, aryballes, vases à figures rouges coupes, oenochoés - utilisés habituellement pour les libations), de statuettes et bustes de femmes-fleurs, d'ossements (de chiens - un de grande taille, l'autre de petite, de chèvres, de chats, de coq) et de bois en partie carbonisé. Il s'agit, selon M. Dewailly, 1997, p. 201-202, des résidus de sacrifices accomplis sur un autel placé à proximité, à 2,3 m à l'est. Tout au fond, s'étend une couche de sable pur.

435 Dont les reproductions sont rassemblées dans P. Defosse, 1971. Sur ces urnes, cf. aussi E. Simon, 1997 ; J.-R. Jannot, 1998, p. 86-87.

${ }^{436}$ Cf. E. Simon, 1997, p. 453.

437 Dans lequel P. Defosse, 1971, p. 499 propose de reconnaître la divinité Calu et E. Simon, 1997, p. 453 un « démon-loup»; pour J.-R. Jannot, 1998, p. 87 "l'être surnaturel qui sort du puits est [...] le porteur de la mort, il est la mort ».

438 Avec des connotations psychologiques différentes, la présence d'un loup permettant sans doute d'insister sur l'aspect terrifiant du rapt. 
sur une urne du musée de Florence ${ }^{439}$ (fig. 29), le chien-loup, sorti à demi d'un puits, qui tente de s'emparer d'un homme à genoux, en présence d'une divinité ailée vraisemblablement Vanth, la déesse de la mort ${ }^{440}$, est maintenu par un personnage assis à l'aide d'une corde, tandis qu'un autre, sans doute un prêtre ${ }^{441}$, verse sur sa tête une libation; sur une urne du musée de $\operatorname{Volterra}^{442}$ (fig. 30), la mise en scène et les gestes sont les mêmes mais l'animal s'avère plus clairement encore être un chien, les personnages sont tous armés et la figure ailée est absente. Ces deux urnes empreintes d'une grande violence révèlent, quelle que soit l'interprétation mythologique que l'on peut leur donner ${ }^{43}$, combien le chien/loup est lié, chez les Etrusques, au monde souterrain et plus encore à la frontière entre la mort et la vie; elles affirment aussi la puissance du rituel - ici la libation - capable de dompter les forces chthoniennes ${ }^{444}$.

Les chiens utilisés dans les rituels funéraires de Poggio Gramignano et de l'agora d'Athènes apparaissent aussi comme les gardiens vigilants des frontières de la vie et de la mort. Leurs os retrouvés à côté des corps de nouveau-nés ${ }^{445}$ répondent assurément à une double volonté : celle de faciliter leur passage dans le monde des morts et plus encore celle d'empêcher leur retour dans celui des vivants ${ }^{446}$. En effet, les morts prématurés $(\text { ahoroi })^{447}$, dans l'imaginaire de ces peuples, comme en témoigne Tertullien $^{448}$, étaient suceptibles d'errer sur terre « jusqu'à ce que le temps qui leur était

${ }^{439}$ Cf. P. Defosse, 1971 planche II.

${ }^{440}$ E. Simon, 1997, p. 453 ; J.-R. Jannot, 1997, p. 87.

${ }^{441}$ Selon J.-R. Jannot, 1998, p. 87 en raison de « son geste et de sa coiffure ».

${ }^{442}$ Cf. P. Defosse, 1971 planche III.

443 Certains commentateurs ont proposé d'y voir le mythe de Circé, d'autres celui d'Iphigénie, d'autres une évocation du voyage d'Ulysse aux Enfers, ... Cf. pour l'inventaire de ces propositions: P. Defosse, 1971, p. 492-493. Plus récemment E. Simon, 1997 propose d'y voir le mythe de Sisyphe.

${ }^{444}$ Du moins de les apaiser provisoirement : cf. J.-R. Jannot, 1998, p. 87 qui parle de « libation purificatrice ou apaisante ».

445 Ce mode d'enterrement peut surprendre, mais il est vrai, à en croire Plutarque, Consolation à sa femme 11 que les très jeunes enfants n'avaient pas les mêmes funérailles que les autres habitants : "A ses enfants morts en bas âge on n'offre pas de libations et à leur égard on ne pratique pas les autres rites qu'il est naturel d'observer pour les autres morts; car ces enfants ne tiennent en aucune façon à la terre ni aux choses de la terre. On ne s'attarde pas à leurs funérailles, près de leurs tombes, de l'endroit où l'on expose leurs corps, et on ne se tient pas auprès d'eux. Les lois ne nous laissent pas donner les marques du deuil à des morts d'un âge aussi tendre, parce que ce serait une impiété à l'égard de ces êtres qui sont passés dans une condition et un séjour meilleur et plus divin $»$.

${ }^{446}$ Ces chiens déposés devaient remplir aux yeux de ces peuples le rôle dévolu à Cerbère.

447 Il s'agit là des morts les plus prématurées qui soient, cf. Plutarque, Consolation à Apollonios, 23 : «Et s'il est vrai que la mort prématurée est un mal, la plus prématurée est sans doute celle des enfants et des petits enfants, et plus encore celle des nouveaunés ».

448 Tertullien, De Anima 57, 3. Cf. aussi Plaute, Mostellaria 497-502 : le revenant inventé par Tranio n'a pas eu accès aux Enfers en raison de sa mort prématurée et parce qu'il repose insepultus («Je suis Diapontius, un hôte d'outre-mer. J'habite ici; cette habitation est devenue mienne. Car Orcus n'a pas voulu me recevoir sur les bords de l'Achéron, parce que j'ai perdu prématurément (praemature) la vie. Je fus victime 
destiné se soit écoulé $\rangle^{449}$, animés le plus souvent par le ressentiment. Ces rituels canins avaient pour objet rendre irréversible la séparation de ces défunts potentiellement dangereux et des vivants ${ }^{450}$.

Aux sanctuaires siciliens d'Héphaïstos et d'Adranos, les chiens marquent pareillement la limite, cette fois entre le sacré et le profane, en régulant l'accès des fidèles au temple : «A Aetna en Sicile, on honore un temple d'Héphaïstos qui comprend une enceinte, des arbres sacrés, un feu qui brûle perpétuellement. Autour du temple et du bois se tiennent des chiens sacrés. Ils accueillent en remuant la queue et flattent les gens bien intentionnés qui s'approchent du temple et du bois dans une attitude convenable comme s'ils éprouvaient à leur égard de la bienveillance et, je suppose, comme s'ils les reconnaissaient. Mais si c'est un homme aux mains souillées par un crime, ils le mordent et le déchirent; en revanche ils se contentent de chasser ceux qui sortent de quelque débauche. [...] Adranon est une ville de Sicile [...] et, dans cette ville se trouve un temple d'Adranos, une divinité locale. [...] Il y a des chiens sacrés qui sont ses serviteurs et ses ministres. Ils dépassent en beauté et aussi en taille les molosses. Ils ne sont pas moins de mille. Le jour ils accueillent et font fête aux visiteurs $\mathrm{du}$ temple et du bois qu'ils soient étrangers ou indigènes. La nuit, ils accompagnent gentiment à la manière de gardes du corps ou de guides ceux qui sont ivres et titubent le long du chemin, raccompagnant chacun chez lui et ils exigent la juste punition des gens pris de boisson. Ils s'élancent en effet sur eux et déchirent leur vêtement. Ils leur donnent ainsi une leçon. Mais ceux qui tentent de voler, ils les mettent en pièces cruellement ${ }^{451}$. En Daunie, dans le lieu de culte d'Athéna Ilias, « ils accueillent les visiteurs grecs et poursuivent de leurs aboiements les barbares $\|^{452}$. Véritables « exécuteurs de la punition divine ${ }^{453}$, les chiens sélectionnent, traquent les différentes formes d'impiété, séparent le pur de l'impur.

Cette dernière fonction se retrouve dans les cérémonies de l'armée macédonienne ${ }^{454}$, au cours desquelles la chienne coupée en deux sert à tracer des limites entre d'une part le monde du souillé et de la mort et d'autre part celui du pur et de la vie, préservant ainsi les soldats regroupés à l'intérieur de cette frontière ${ }^{455}$, dans un espace vierge de toute impureté, loin duquel sont tenues en respect les divinités infernales promptes à se

d'une perfidie ; mon hôte m'assassina et m'enfouit sans sépulture, secrètement, dans cette maison même ».

${ }^{449}$ U. Lugli, 2006, p. 241. Aussi, comme le souligne J.-P. Néraudau, 1987, p. 195, « de tout temps, à Rome, la mort prématurée fut l'objet de rites et de comportements spécifiques $»$.

${ }^{450}$ Sur la séparation nécessaire et rigoureuse des morts et des vivants, que s'attachent à mettre en scène les rites de funérailles, cf. J. Maurin, 1984; J. Scheid, 1984 ; L. Deschamps, 1995, p. 179 ; M. Ducos, 1995, p. 135.

${ }^{451}$ Elien, $N A$, XI, 3.

452 Elien, NA, XI, 5. R. Robert, 1993, p. 132 propose d'y voir « une interprétation locale " d'un épisode de la vie légendaire de Diomède dont les compagnons métamorphosés en oiseaux se montraient amicaux avec les Grecs et malveillants avec les Barbares (cf. Lycophron, Alexandre 592-632).

${ }^{453}$ N. Cusumano, 1992, p. 157.

${ }^{454}$ Cf. Tite-Live, XL, 6, 1-3 ; Quinte-Curce, X, 9, 12.

${ }^{455} \mathrm{Ce}$ qui peut rappeler la lustratio romaine qui « définit et constitue une chose ou un groupe » : J. Scheid, 1999, p. 187. 
réveiller au début des combats : seul le chien par son appartenance conjointe aux deux mondes convenait à un tel rituel ${ }^{456}$.

\section{2. 4. Eux-mêmes divisés}

Il n'est sans doute pas anodin, non plus, que cet animal qui signifie plus que tout autre la séparation, l'appartenance à plusieurs mondes soit, au cours des rituels qui ont recours à lui, la cible quasi systématique de démembrements plus ou moins complexes $^{457}$. A Sparte, les « jeunes chiens sont coupés en deux $»^{458}$. En Béotie, c'est « entre les deux morceaux d'un chien coupé par le milieu » que se déroule la cérémonie de purification publique ${ }^{459}$. La lustration macédonienne nécessite elle aussi le dépeçage d'une chienne : " on coupe une chienne à mi-corps, on place la partie comprenant la tête sur la droite d'une route et la partie postérieure, avec les entrailles, sur la gauche ; on fait défiler les troupes en armes entre les morceaux de cette victime $»^{460}$. "Discissa ${ }^{461}$, «praecisa $»^{462}$, «diuisa $»^{463}$, tels sont les qualificatifs de cette victime sacrificielle, tous rattachés au champ lexical de la scission. Le chien sacrifié chez les Eléens est lui aussi «fendu en deux, laissant apparaître son foie " ${ }^{464}$. A Gubbio, l'officiant découpe (prusekatu, prusektu ${ }^{465}$ ) le chien en trois parties, en en réservant une comme erus ${ }^{466}$, une part sacrée. Les témoignages archéologiques attestent eux aussi de telles pratiques. Les Ombriens romanisés de Poggio Gramignano pratiquent ainsi des démembrements complexes : sur les treize squelettes retrouvés, seuls quatre sont à peu près intacts; un autre n'a plus que la tête, laquelle à l'inverse fait défaut à l'exemplaire le plus âgé ; quatre autres ont encore la partie supérieure du crâne et le reste des os mais pas les mandibules; trois autres enfin ont les mandibules et les os du corps mais pas le crâne (fig. 31) ${ }^{467}$. Le chien des remparts de Paestum, dont on a retrouvé seulement une partie des os (regroupés ${ }^{468}$ ) du squelette ${ }^{469}$ a sans doute subi un tel sort, tout comme celui

456 Aussi, faut-il se défier de l'interprétation proposée par R. Robert, 1993, p. 194 qui voit dans ce rituel « la volonté de retrouver une cohésion perdue ».

${ }^{457}$ Le démembrement (dont la décapitation) des chiens a été pratiqué en d'autres temps - archaïques - , cf. M. MacKinnon, 1998, p. 548 et L. Larsson, 1991, p. 33-38, et en d'autres lieux (chez les Hittites, par exemple, cf. B. J. Collins, 1990, p. 218, 223).

458 Plutarque, Questions Romaines 111.

459 Plutarque, Questions romaines 111.

460 Tite-Live, XL, 6, 1-3.

${ }^{461}$ Quinte-Curce, X, 9, 12.

462 Tite-Live, XL, 6, 1.

463 Tite-Live, XL, 6, 2.

464 Pausanias VI, $2,4$.

465 TE IIa 28. La répétition très proche de ce verbe montre l'importance de cet acte dans le sacrifice du chien.

${ }^{466}$ L'erus, qui revient souvent dans les Tables (TE Ia 33, Ib 34, 35, 36 ; IIa 9, 28, 32 , 40 ; IIb 21 ; IV, 14, 27) a été l'objet d'interprétations diverses. Le mot pourrait provenir d'un *aisus et désigner "la partie sacrée, c'est-à-dire consacrée aux dieux » (A. L. Prosdocimi, 1984, p. 3336), «il pertinente al dio, la cosa divina» (A. Ancillotti, R. Cerri, 1996, p. 359 qui le traduit, par la formule quelque peu anachronique de « Santa Offerta »; cf. aussi G. Devoto, 1948, p. 20 qui parle de « communio praecristiana »!).

467 Cf. M. MacKinnon, 1998 fig. 309-310.

${ }^{468}$ Cf. R. Robert, 1993, p. 123. 
d'Ariminum dont il reste moins de la moitié du squelette ${ }^{470}$ : les explications environnementales ${ }^{471}$ avancées jusqu'ici n'emportaient d'ailleurs pas la conviction de ceux mêmes qui les formulaient ; sans doute, ces chiens ont-ils été découpés au cours de rituels, comme l'étaient ceux des cérémonies grecques et ombrienne ; peut-être même, comme le suggère G. Giusberti, des parties de l'animal ont-elles été dispersées en plusieurs points de la muraille, afin d'en étendre la protection ${ }^{472}$. Tout aussi incomplets apparaissent les squelettes retrouvés à Torre di Satriano ou dans l'heraion du Sele.

$\mathrm{Au}$ cours de tous ces rituels, les chiens sont donc découpés, souvent désarticulés ${ }^{473}$, parfois décapités ${ }^{474}$, comme si les officiants cherchaient à séparer les composantes contradictoires - pures et souillées, chthoniennes et ouraniennes, ... - de cet animal ambivalent. La séparation puis la répartition des parties découpées devaient obéir à des règles strictes - variables selon les communautés - dont nous avons un aperçu - certes bien obscur - dans les Tables Eugubines : des morceaux (les supa) sont cuits et placés dans un plat, d'autres reçoivent des prières, d'autres (les sufafiaf) sont émiettés (dans un geste d'ultime scission); mais c'est l'erus - sans aucun doute une part de prestige destinée au dieu - qui est l'objet de toutes les attentions : porté dans la main, il est offert sur l'autel; l'erus est probablement constitué par l'iepru ${ }^{475}$ dans lequel certains traducteurs proposent de voir le foie ${ }^{476}$ - un organe où les Anciens - les Etrusques, notamment - plaçaient le siège de la vie ${ }^{477}$; cette hypothèse apparaît plus séduisante

${ }^{469}$ Ce qui laissait perplexe M. Leguilloux, 1993, p 141-142: « on ne sait si l'absence d'une partie importante du squelette est le résultat du hasard ou s'il s'agit d'une sélection volontaire $»$.

${ }^{470}$ Cf. G. Giusberti, 1990, p. 119.

471 Pour le squelette de Paestum, R. Robert, 1993, p. 123, n. 4 a proposé plusieurs hypothèses : " Il n'est pas impossible qu'une partie du squelette se trouve encore prise dans la berme est, partie non-fouillée de l'excavation. [...] Le mauvais état de conservation des ossements et la disparition d'un certain nombre d'entre eux vient sans doute de l'humidité dans laquelle a baigné cette zone»; pour celui d'Ariminum, G. Giusberti, 1990, p. 119 propose, entre autres, d'y voir l'action destructive d'un fouisseur (hérisson, taupe?), ou un effet de la modification du mur à l'époque médiévale.

472 G. Giusberti, 1990, p. 119.

${ }^{473}$ Le rituel romain de la crucifixion canine semble répondre à une volonté identique d'écartèlement (cf. Pline l'Ancien, XXIX, 57: «Nous avons parlé de l'honneur que méritèrent les oies pour avoir signalé l'escalade du Capitole par les Gaulois. C'est pour la même raison que l'on crucifie chaque année, entre le temple de la Jeunesse et celui de Summanus, des chiens attachés vivants par les épaules à une fourche de sureau »).

474 On pourrait parler d'une véritable obsession de la séparation, proche de ce que la psychanalyse nomme la Spaltung pour caractériser certaines attitudes autistes et schizophrènes (cf. E. Minkowski, 1927; G. Durand, 1984, p. 210 qui constate que «sans cesse reviennent dans les descriptions schizomorphes des termes tels que « coupé, partagé, séparé, divisé en deux, fragmenté, ébréché, déchiqueté, rongé, dissous $[\ldots] »)$.

475 TE IIa 32.

476 Ainsi A. Blumenthal, 1931, p. 65 ; V. Pisani, 1964, p. 200 ; J. W. Poultney, 1959, p. 96, 185, 310 ; A. Ancillotti, R. Cerri, 1996, p. 374. Il est tentant, en effet, de rapprocher iepru du latin iecur, du grec $\tilde{\eta} \pi \alpha \rho$. D'autres, comme G. Devoto, 1962, p. 343 et A. J. Pfiffig, 1964, p. 15 y voient plus curieusement un adverbe.

477 D. Briquel, 2003, p. 255. 
encore quand on la rapproche d'une comparaison faite par Plutarque qui associe la position du foie dans le corps, entre le coeur et les intestins, et celle de la lune ${ }^{478}$ entre le soleil et la terre ${ }^{479}$ : la nature même de cet organe n'apparaissait-elle pas aux Anciens analogue à celle de la lune qui est appelée " par les uns « l'astre terrestre », par d'autres « la terre olympienne », par d'autres enfin « le domaine de la déesse à la fois souterraine et céleste » ${ }^{480}$ ? D’ailleurs, dans le monde étrusque voisin, le «foie de Plaisance » est organisé en deux parties séparées par l'incisura umbilicalis : l'une « solaire » (usils) - la "pars familiaris » diraient les Latins, dominée par la figure de Tinia ; l'autre " lunaire» (tivs) - la "pars hostilis », domaine de divinités plus sombres comme Selans, voire infernales comme Letha ${ }^{481}$. Le foie du chien paraît résolument la part la plus appropriée au dieu ambivalent Hunte Iuuie ${ }^{482}$.

L'étude des sacrifices canins et plus largement de la place du chien dans les rites peut donc permettre d'éclaircir quelques séquences rituelles obscures comme l'Huntia des frères atiédiens, les Robigalia et les Lupercales des Romains et de mieux cerner le visage de divinités mal connues comme Hunte Iuuie, Genita Mana ou Robigo.

Les Grecs, les Etrusques, les Italiques comme les Romains font du chien une utilisation rituelle fort diversifiée - ce qui ne fait que confirmer une fois de plus le cloisonnement rituel bien connu des sociétés antiques - et toujours très encadrée. Dans ces communautés, les sacrifices canins n'ont rien d' "extra-ordinaire ": ils sont seulement moins fréquents que les offrandes de bovins ou d'ovins et sont surtout peu à peu tombés en désuétude en raison du nouveau « statut social » dévolu au fil du temps à cet animal.

Pour autant, des homologies apparaissent dans la nature des divinités concernées et dans le rôle implicitement joué par le chien dans ces rites : tant à Rome, qu'à Gubbio, Pyrgi, Cortona ou Paestum, les sacrifices canins honorent des divinités ambivalentes qui veillent sur les seuils, par l'offrande en des lieux de passages - puits, entrées de sanctuaires, carrefours, remparts - d'un animal également contradictoire, sentinelle des limites, dont le corps même est divisé selon des modalités diverses mais toujours réfléchies. Les rituels canins semblent partout accomplis sous le régime de la séparation.

Jean-Claude Lacam (Université Paris 1 / Centre Gustave-Glotz)

478 Qui joue d'ailleurs un rôle important dans les Tables: 1'Huntia se déroule au moment de la pleine lune.

${ }^{479}$ Plutarque, De Facie quae in orbe lunae apparet, 928c.

${ }^{480}$ Plutarque, De Defectu oraculorum, 416 A.

${ }^{481}$ Cf. A. Maggiani, 1982 ; D. Briquel, 2003, p. 254-255.

${ }^{482}$ C'est sans doute pour cette raison que la nature de l'erus est clairement explicité dans cette cérémonie et que son importance est soulignée avec un soin tout particulier. 


\section{BIBLIOGRAPHIE}

Les abréviations utilisées pour citer les périodiques sont celles de l'Année Philologique.

A. Ancillotti, R. Cerri, 1996 : A. Ancillotti, R. Cerri, Le tavole di Gubbio e la civiltà degli Umbri, Pérouse, 1996.

J. L. Angel, 1945 : J. L. Angel, 1945, Skeletal Material from Attica, dans Hesperia, 14, 1945, p. 279-363.

J. Bayet, 1926 : J. Bayet, Les origines de l'Hercule romain, Paris, 1926, p. 454-457.

J. Bayet, 1971 : J. Bayet, Les Cerialia : altération d'un culte latin par le mythe grec, dans J. Bayet, Croyances et rites dans la Rome antique, Paris, 1971, p. 89-129.

R. Bianchi Bandinelli, 1961 : R. Bianchi Bandinelli (éd.), Enciclopedia dell'arte antica, Roma, 1961.

F. Blaive, 1995 : F. Blaive, Le rituel romain des Robigalia et le sacrifice du chien dans le monde indo-européen, dans Latomus, 54, 24, 1995, p. 279-289.

R. Bloch, 1958 : R. Bloch, Sur les danses armées des Saliens, dans Annales E. S. C. 13, 1958, p. 706-715.

R. Bloch, 1968 : R. Bloch, Ilithyie, Leucothée et Thesan, dans CRAI, 1968, p. 366-375.

A. Blumenthal, 1931 : A. Blumenthal, Die Iguvischen Tafeln, Stuttgart, 1931.

F. Bömer, 1958 : Ovid, Die Fasten. Tome II (F. Bömer : Kommentar), Heidelberg, 1958.

G. Boni, 1899 : G. Boni, 1899 : G. Boni, La suppellettile archeologica trovata sotto il Lapis Niger nel Foro Romano, dans NS, 24, 1899, p. 158, 168.

G. Boni, 1900 : G. Boni, Le recenti esplorazioni nel sacrario di Vesta, dans NS, 25, 1900, p. 173-174.

P. Borgeaud, 1986 : P. Borgeaud, Le problème du comparatisme en histoire des religions, dans Revue européenne des sciences sociales, 24, 1986, $\mathrm{n}^{\circ} 72$, p. 59-75.

F. Braudel, 1986 : F. Braudel, L'identité de la France, Paris, 1986.

J. Bremmer, 1994 : J. Bremmer, Greek Religion, Oxford, 1994.

D. Briquel, 2003 : D. Briquel, La civilisation étrusque, Paris, 2003.

L. Bruidt Zaidman, P. Schmitt Pantel, 1991 : L. Bruidt Zaidman, P. Schmitt Pantel, La religion grecque, Paris, 1991.

S. Bruni, 2002 : S. Bruni, Nugae de etruscorum fabulis, dans Ostraka 11, 1, 2002, p. 728.

S. Bruni, 2003 : S. Bruni, Il santuario di Ortaglia nel territorio volterrano : appunti sulle pratiche cultuali, dans AA. VV., Offerte dal regno animale e dal regno vegetale nella dimensione del sacro, Incontro di studi, Milano, 2003.

L. Caloi, M. -R. Palombo, 1980 : L. Caloi, M.-R. Palombo, Il cane domestico di Pyrgi, dans $S E, 48,1980$, p. 293-328.

A. Carandini, 1997 : A. Carandini, La nascita di Roma, Dèi, Lari, eroi e uomini all'alba di una civiltà, Turin, 1997.

J. Champeaux, 1987 : J. Champeaux, Fortuna, Recherches sur le culte de la Fortune à Rome et dans le monde romain des origines à la mort de César, Rome, 1987.

L. Chazalon, 1995 : L. Chazalon, Héraclès, Cerbère et la porte des Enfers dans la céramique attique, dans A. Rousselle (éd.), dans Frontières terrestres, frontières célestes dans l'Antiquité, Paris, 1995, p. 165-187.

C. Chiaromonte Treré, 1988 : C. Chiaromonte Treré, I depositi all'ingresso dell'edificio tarquiniese: nuovi dati sui costumi rituali etruschi, dans MEFRA, 100, 2, 1988, p. 565-600. 
M. Cipriani, 1997: M. Cipriani, Il ruolo di Hera nel santuario meridionale di Poseidonia, dans J. de La Genière (éd.), Héra; Images, espaces, cultes (Actes du Colloque International du Centre de Recherches Archéologiques de l'Université de Lille III et de l'Association P.R.A.C., Lille, 29-30 novembre 1993), Naples, 1997, p. 211-226.

R. Cirilli, 1912 : R. Cirilli, Le sacrifice du chien, dans Revue anthropologique, 8, 1912, p. 325-334.

F. Coarelli, 1983 : F. Coarelli, Il Foro Romano. Periodo arcaico, Rome, 1983.

F. Coarelli, 1993 : F. Coarelli, Lares Praestites, dans E. M. Steinby (éd.), Lexicon topographicum urbis Romae, Rome, 1993.

B. J. Collins, 1990: B. J. Collins, The Puppy in Hittite Ritual, dans Journal of Cuneiform Studies, 42 (2), 1990, p. 211-226.

M. Corsano, 1977 : M. Corsano, 'Sodalitas' et gentilité dans l'ensemble lupercal, dans RHR, 191.2, 1977, p. 137-158.

G. Colonna, 1981: G. Colonna, La dea di Pyrgi: bilancio aggiornato dei dati archeologici (1978), dans Akten des Kolloquiums zum Tema "Die Göttin von Pyrgi », Tübingen 1979, Florence, 1981.

G. Colonna, 1997 : G. Colonna, Divinités peu connues du panthéon étrusque, dans F. Gautier, D. Briquel, (éd.), Les Etrusques. Les plus religieux des hommes. Etat de la recherche sur la religion étrusque (Actes du colloque international, Galeries nationales du Grand Palais, 17-18-19 novembre 1992), Paris, 1997, p. 167-184.

G. Colonna, E. Colonna di Paolo, 1978 : G. Colonna, E. Colonna di Paolo, Norchia, I, Rome, 1978.

E. Colonna di Paolo, 1978 : E. Colonna di Paolo, Necropoli rupestri del Viterbese, Novare, 1978.

M. Crawford, 1974 : M. Crawford, Roman Republican Coinage, Londres, 1974.

M. Cristofani, 1997 : M. Cristofani, Masculin/féminin dans la théonymie étrusque, dans F. Gautier, D. Briquel, (éd.), Les Etrusques. Les plus religieux des hommes. Etat de la recherche sur la religion étrusque (Actes du colloque international, Galeries nationales du Grand Palais, 17-18-19 novembre 1992), Paris, 1997, p. 209-219.

N. Cusumano, 1992 : N. Cusumano, I culti di Adrano e di Efesto. Religione, politica e acculturazione in Sicilia tra V e IV secolo, dans Kokalos, XXXVIII, 1992, p. 151189.

L. P. Day, 1984 : L. P. Day, Dogs burials in the Greek World, AJA 1984, LXXXVIII, p. 21-32.

P. Defosse, 1971 : P. Defosse, Génie funéraire ravisseur (Calu) sur quelques urnes étrusques, dans L'Antiquité Classique, 41, 1972, p. 487-499.

L. Delatte, 1937 : L. Delatte, Recherches sur quelques fêtes mobiles du calendrier romain, dans $A C, 6,1937$, p. 93-117.

J. De Grossi Mazzorin, 2001 : J. De Grossi Mazzorin, L'uso dei cani nei riti funerari, dans Culto dei morti e costumi funerari romani, Palilia, 8, 2001, p. 77-82.

C. de Simone, 1997: C. de Simone, Dénominations divines étrusques binaires: considérations préliminaires, dans F. Gautier, D. Briquel, (éd.), Les Etrusques. Les plus religieux des hommes. Etat de la recherche sur la religion étrusque (Actes du colloque international, Galeries nationales du Grand Palais, 17-18-19 novembre 1992), Paris, 1997, p. 185-208.

L. Deschamps, 1995 : L. Deschamps, Rites funéraires de la Rome républicaine, dans F. Hinard (éd.), La mort au quotidien dans le monde romain, Actes du colloque organisé par l'Université de Paris IV (Paris - Sorbonne 7-9 octobre 1993), 1995, p. 171-180. 
M. Détienne, 2000 : M. Détienne, Comparer l'incomparable, Paris, 2000.

L. Deubner, 1960 : L. Deubner, Attische Feste, Berlin, 1960.

G. Devoto, 1948 : G. Devoto, Le tavole di Gubbio, Florence, 1948.

G. Devoto, 1954 : G. Devoto, Tabulae iguvinae, Rome, 1954.

G. Devoto, 1962 : G. Devoto, Tabulae iguvinae, Rome, 1962.

G. Devoto, 1967 : G. Devoto, Gli Antichi Italici, Florence, 1967.

M. Dewailly, 1997 : M. Dewailly, L'heraion de Foce del Sele: quelques aspects du culte d'Héra à l'époque hellénistique d'après les terres cuites, dans J. de La Genière (éd.), Héra ; Images, espaces, cultes (Actes du Colloque International du Centre de Recherches Archéologiques de l'Université de Lille III et de l'Association P.R.A.C., Lille, 29-30 novembre 1993), Naples, 1997, p. 201-210.

M. Ducos, 1995 : M. Ducos, Le tombeau, Locus religiosus, dans F. Hinard (éd.), La mort au quotidien dans le monde romain, Actes du colloque organisé par l'Université de Paris IV (Paris - Sorbonne 7-9 octobre 1993), 1995, p. 135-144.

G. Dumézil, 1987 : G. Dumézil, La Religion romaine archaïque, Paris, 1987.

G. Dumézil, 2003 : G. Dumézil, La triple Hécate (1985), dans G. Dumézil, Esquisses de mythologie, Paris, 2003.

G. Durand, 1984 : G. Durand, Les structures anthropologiques de l'imaginaire, Paris, 1984.

C. M. Edwards, 1984 : C. M. Edwards, Aphrodite on a ladder, dans Hesperia, 53, 1984, p. 59-72.

A. Ernout, 1961 : A. Ernout, Le Dialecte ombrien. Lexique du vocabulaire des Tables Eugubines, Paris, 1961.

P. Farello, 1990: P. Farello, Casale di Rivalta. Reperti faunistici, dans Vestigia Crustunei. Insediamenti etruschi lungo il corso del Crostolo, Reggio Emilia, 1990, p. 244, 254, tav. LXXVI.

A. Franchi de Bellis, 1981 : A. Franchi de Bellis, Le Iovile capuane, Florence, 1981.

A. Gianferrari, 1995 : A. Gianferrari, Robigalia : un appuntamento per la salvezza del raccolto, dans L. Quilici (éd.), Agricoltura e commerci, 1995, p. 127-140.

G. Giusberti, 1990 : G. Giusberti, I resti ossei sacrificali delle mura di Ariminum, dans Etudes Celtiques, 27, 1990, p. 103-130.

E. Gjerstad, 1960 : E. Gjerstad, Early Rome, III, Fortifications, domestic architecture, sanctuaries, stratigraphic excavations, Lund, 1960.

E. Greco, 1981 : E. Greco, Magna Grecia, Rome-Bari, 1981.

C. H. Greenewalt, 1978 : C. H. Greenewalt Jr, Ritual Dinners in Early Greek Sardis, Berkeley-Los Angeles-London, 1978.

E. B. Harrison, 1965 : E. B. Harrison, The Athenian Agora, XI : Archaic and Archaistic Sculpture, Princeton, 1965.

E. C. Haspels, 1971 : E. C. Haspels, The Highlands of Phrygia I, 1971.

G. Herrlinger, 1930: G. Herrlinger, Totenklage um Tiere in der antiken Dichtung, Stuttgart, 1930.

J. Heurgon, 1942 : J. Heurgon, Etudes sur les inscriptions osques de Capoue dites iúvilas, Alger, 1942.

J. Heurgon, 1970 : J. Heurgon, Recherches sur l'histoire, la religion et la civilisation de Capoue préromaine des origines à la deuxième guerre punique, Paris, 2è éd., 1970.

G. Ioppolo, 1971-1972 : G. Ioppolo, I reperti ossei nell'area di S. Omobono (19621964), dans Rendiconti della Pont. Accad. rom. d'Arch., 44, 1971-1972, p. 5-19.

A. Jacquemin, 2005 : A. Jacquemin, article « Héra », dans J. Leclant (éd.), Dictionnaire de l'Antiquité, Paris, 2005, p. 1026. 
J.-R. Jannot, 1997 : J.-R. Jannot, Charu(n) et Vanth, divinités plurielles ?, dans F. Gautier, D. Briquel, (éd.), Les Etrusques. Les plus religieux des hommes. Etat de la recherche sur la religion étrusque (Actes du colloque international, Galeries nationales du Grand Palais, 17-18-19 novembre 1992), Paris, 1997, p. 139-165.

J.-R. Jannot, 1998 : J.-R. Jannot, Devins, dieux et démons : regards sur la religion de l'Etrurie antique, Paris, 1998.

S. I. Johnston, 1990 : S. I. Johnston, Hekate Soteira, Atlanta, 1990.

L. Kahn, 1978 : L. Kahn, Hermès passe, Paris, 1978.

L. Kahn, 1979 : L. Kahn, Hermès et la frontière ambiguë, dans Ktema 4, 1979, p. 201211.

Th. Kraus, 1960 : Th. Kraus, Hekate, Heidelberg, 1960.

K. Latte, 1960 : K. Latte, Römische Religionsgeschichte, Munich, 1960.

L. Larsson, 1991 : L. Larsson, Symbolism and Mortuary Practice. Dogs in FractionsSymbols in Action, dans Archeology and Environment, 11, 1991, p. 33-38.

H. Le Bonniec, 1958 : H. Le Bonniec, Le culte de Cérès à Rome, Paris, 1958.

M. Leguilloux, 1993 : M. Leguilloux, Appendice, dans R. Robert, 1993, p. 141-142.

S. Lepetz, W. Van Andringa, 2004 : S. Lepetz, W. Van Andringa (éd.), Le sacrifice animal en Gaule romaine. Rituels et pratiques alimentaires, Pré-Actes de la table ronde tenue au Museum d'Histoire Naturelle de Paris, octobre 2002, 2004.

P. Lévêque, 1997 : P. Lévêque, Bilan des travaux. La personnalité d'Héra, dans J. de La Genière (éd.), Héra ; Images, espaces, cultes (Actes du Colloque International du Centre de Recherches Archéologiques de l'Université de Lille III et de l'Association P.R.A.C., Lille, 29-30 novembre 1993), Naples, 1997, p. 267-270.

LIMC : Lexicon Iconographicum Mythologiae Classicae, Zürich München, I, 1981 ; II, 1984 ; III, 1986 ; IV, 1988 ; V, 1990 ; VI, 1992 ; VII, 1994.

B. Liou-Gille, 1980 : B. Liou-Gille, Les cultes 'hérö̈ques' romains. Les fondateurs, I, Paris, 1980.

E. Lissi, 1961: E. Lissi, Gli scavi della scuola nazionale di archeologia a Locri Epizefiri, dans Atti del settimo congresso internazionale di archeologia classica, II, Rome, 1961, p. 109-115.

U. Lugli, 2006 : U. Lugli, La rappresentazione dei revenants nella Roma antica, thèse (E.P.H.E.), Paris, 2006.

R. Macellari, 1990: R. Macellari, Casale di Rivalta. Insediamento con impianti produttivi. Ceramiche attiche e bronzi. Considerazioni conclusive, dans Vestigia Crustunei. Insediamenti etruschi lungo il corso del Crostolo, Reggio Emilia, 1990, p. 196-198.

M. MacKinnon, 1998 : M. Mac Kinnon, Animal Bone Remains, dans D. S. Soren, N. Soren (éd.), Excavations of a Roman Villa and Late Infant Cemetery near Lugnano in Teverina, Italy, Rome, 1998, p. 533-594.

A. Maggiani, 1982 : A. Maggiani, Qualche osservazione sul Fegato di Piacenza, dans $S E, 49,1982$, p. 53-88.

C. Mainoldi, 1984 : C. Mainoldi, L'image du loup et du chien dans la Grèce ancienne d'Homère à Platon, Paris, 1984.

C. Malone, S. Stoddard, 1994 : C. Malone, S. Stoddard, Territory, Time and State. The Archeological Development of the Gubbio Basin, Cambridge, 1994.

O. Masson, 1950: O. Masson, A propos d'un rituel hittite pour la lustration d'une armée: le rite de purification par le passage entre les deux parties d'une victime, dans R.H.R. 137, 1950, p. 5-25.

O. Masson, 1962 : O. Masson, Les fragments du poète Hipponax, Paris, 1962. 
J. Maurin, 1984 : J. Maurin, " Funus » et les rites de séparation, dans AION (archeol.), 6, 1984, p. 191-208.

P. Mencacci, M. Zecchini, 1975 : P. Mencacci, M. Zecchini, La Buca di Castelvenere, dans AttSocToscanaScNat 82, 1975, p. 139 fig. 1.

P. Mencacci, M. Zecchini, 1976 : P. Mencacci, M. Zecchini, Lucca preistorica. Versilia, Valle del Serchio, piana lucchese dal paleolitico alla conquista romana, Lucca, 1976.

P. Méniel, 1992 : P. Méniel, Les sacrifices d'animaux chez les Gaulois, Paris, 1992.

E. Minkowski, 1927 : E. Minkowski, L'autisme et les attitudes schizophréniques, dans Journ. Psycholog., 1927, p. 212-213.

A. Neppi Modona, 1977 : A. Neppi Modona, Cortona etrusca e romana, Florence, 1977.

J.-P. Néraudau, 1987 : J. -P. Néraudau, La loi, la coutume et le chagrin, Réflexions sur la mort des enfants, dans F. Hinard (éd.), La mort, les morts et l'au-delà dans le monde romain, Actes du colloque de Caen 20-22 novembre 1985, Caen, 1987, p. 195-208.

M. Nouilhan, J.-M. Pailler, P. Payen, 1999 : Plutarque, Grecs et Romains en parallèle, Questions romaines. Questions grecques (commentaire de M. Nouilhan, J. -M. Pailler, P. Payen), Paris, 1999.

M. L. Nova, M. Osanna, 2001 : M. L. Nova, M. Osanna (éd.), Rituali per una Dea Lucana, Potenza, 2001.

C. Orrieux, 1997 : C. Orrieux, Hécate, déesse des portes et des carrefours, dans A. Leménorel (éd.), La Rue, lieu de sociabilité ?, Rouen, 1997, p. 273-277.

J. Ortalli, 1990 : J. Ortalli, Le mura coloniali di Ariminum e il deposito monetale di fondazione con semuncia a testa di Gallo, dans Etudes Celtiques 27, 1990, p. 103118.

M. Osanna, T. Giammatteo, 2001 : M. Osanna, T. Giammatteo, Azioni rituali e offerte votive, dans M. L. Nova, M. Osanna (éd.), Rituali per una Dea Lucana, Potenza, 2001, p. 107-122.

M. Osanna, 2004 : M. Osanna, Rituali sacrificali e offerte votive nel santuario lucano di Torre di Satriano, dans Archiv für Religionsgeschichte, VI, 2004, p. 45-62.

M. Pallotino, 1954 : M. Pallottino, Testimonia Linguae Etruscae, Florence, 1954.

M. Pallotino, 1956: M. Pallottino, Deorum sedes, dans Studi in onore di Aristide Calderini e Roberto Paribeni, 3 volumes, Milan, 1956, p. 223-234 (réédité dans M. Pallottino, Saggi di Antichità, 3 volumes, Rome, 1979).

J. G. Pedley, 1974 : J. G. Pedley, Carians in Sardis, dans JHS, 94, 1974, p. 96-99.

P. Pensabene, 1977 : P. Pensabene, Cippi, busti, ritratti. Nota in margine a : M. Kilmer, The Shoulder bust in Sicily and South and Central Italy, Göteborg, 1977, dans ArchClass, 29, 1977, p. 425-435.

A. J. Pfiffig, 1964: A. J. Pfiffig, Religio iguvina. Philologische und Religionsgeschichtliche Studen zu den Tabulae Iguvinae mit Text und übersetzung, Vienne, 1964.

A. Pigagniol, 1923 : A. Pigagniol, Recherches sur les jeux romains, Strasbourg, 1923.

G. Piccaluga, 1963 : G. Piccaluga, L'anti-Jupiter, dans SMSR, 34, 1963, p. 34.

G. B. Pighi, 1954 : G. B. Pighi, I nomi delle divinità iguvine, dans RFIC, 32, 1954, p. 225-261.

V. Pisani, 1964 : V. Pisani, Manuale storico della lingua latina. IV: Le lingue dell'Italia antica i oltre il Latino, Turin, 1964. 
V. Pirenne-Delforge, 1994 : V. Pirenne-Delforge, L'Aphrodite grecque. Contribution à l'étude de ses cultes et de sa personnalité dans le panthéon archaïque et classique, Athènes-Liège, 1994.

V. Pirenne-Delforge, 2005 : V. Pirenne-Delforge, Des épithètes exclusives dans la Grèce polythéiste? L'exemple d'ourania, dans N. Belayche, P. Brulé, G. Freyburger, Y. Lehmann, L. Pernot, F. Prost (éd.), Nommer les Dieux; Théonymes, épithètes, épiclèses dans l'Antiquité, Rennes, 2005, p. 270-291.

D. Porte, 1985 : D. Porte, L'étiologie religieuse dans les Fastes d'Ovide, Paris, 1985.

J. W. Poultney, 1959 : J. W. Poultney, The bronze tables of Iguvium, Baltimore, 1959.

C. Préaux, 1973 : C. Préaux, La Lune dans la pensée grecque, Bruxelles, 1973.

A. L. Prosdocimi, 1978 : A. L. Prosdocimi, L'Umbro, dans Lingue e dialetti dell'Italia antica, Popoli e civiltà dell'Italia antica, VI, Rome, 1978, p. 585-787.

A. L. Prosdocimi, 1984 : A. L. Prosdocimi, Rite et sacrifice dans les tables d'Iguvium, dans Sodalitas. Scritti in onore di A. Guarino, Naples, 1984, p. 3317-3340.

A. L. Prosdocimi, 1989 : A. L. Prosdocimi, Le religioni degli Italici, dans C. Ampolo, D. Briquel, P. Cassola (éd.), Italia omnium terrarum parens. La civiltà degli Enotri, Choni, Ausoni, Sanniti, Lucani, Bretti, Sicani, Siculi, Elimi, Milan, 1989, p. 477-545.

A. L. Prosdocimi, 1996 : A. L. Prosdocimi, La tavola di Agnone. Una interpretazione, dans L. del Tutto Palma (éd.), La Tavola di Agnone nel contesto italico, Convegno di Studio, Agnone, 13-15 aprile 1994, Florence, 1996, p. 435-630.

W. Prummel, 1996 : W. Prummel, The sacrificial animals in deposit II of Borgo Le Ferriere (Satricum), dans J. W. Bouma (éd.), Religio Votiva: the Archeology of Latial Votive Religion. The 5th-3rd BC Votive Deposit South West of the main Temple at « Satricum » Borgo Le Ferriere, Groningen, 1996, p. 419-481.

P. Raingeard, 1934 : P. Raingeard, Hermès Psychagogue, Essai sur les Origines du Culte d'Hermès, Rennes, 1934.

H. Rix, 1981 : H. Rix, Rapporti onomastici fra il pantheon etrusco e quello romano, dans Gli Etruschi e Roma. Incontro di studio in onore di Massimo Pallottino, Roma, 11-13 dicembre 1979, Rome, 1981, p. 104-126.

J.-N. Robert, 1985 : J.-N. Robert, Vie à la campagne dans l'Antiquité romaine, Paris, 1985.

R. Robert, 1993 : R. Robert, Rites de protection et de défense, AION (archéol.), 1993, 15, p. 119-142.

F. Roncalli, 1985 : F. Roncalli, I santuari dei Duodecim Populi e i santuari orvietani, dans AnnFaina 2, 1985, p. 66-67.

F. Roncalli, 1997 : F. Roncalli, Iconographie funéraire et topographie de l'au-delà en Etrurie, dans F. Gautier, D. Briquel, (éd.), Les Etrusques. Les plus religieux des hommes. Etat de la recherche sur la religion étrusque (Actes du colloque international, Galeries nationales du Grand Palais, 17-18-19 novembre 1992), Paris, 1997, p. 37-56.

R. Rosenzweig, 1999 : R. Rosenzweig, Aphrodite in Athens : a study of art and cult in the classical and late classical periods, University of Oregon, 1999.

D. Sabbatucci, 1988 : D. Sabbatucci, La religione di Roma antica. Dal calendario festivo all'ordine cosmico, Milan, 1988.

E. Samter, 1910 : E. Samter, article "Genita Mana », Paulys Realencyclopädie der classischen Altertumswissenschaft, Stuttgart, 1910, VI, 2, p. 1154-1155.

C. Santini, 1991 : C. Santini, Fast. 4, 905-942: ruggine del grano e ruggine del ferro, dans I. Gallo, L. Nicastri (éd.), Cultura, poesia, ideologia nell'opera di Ovidio, 1991, p. $169-182$. 
J. Scheid, 1984 : J. Scheid, "Contraria facere » : renversements et déplacements dans les rites funéraires, dans AION (archeol.), 6, 1984, p. 117-139.

J. Scheid, 1990 : J. Scheid, Romulus et ses frères. Le collège des frères arvales, modèle du culte public dans la Rome des empereurs, Rome, 1990.

J. Scheid, 1997 : J. Scheid, Comment identifier un lieu de culte?, dans Cahiers du centre Gustave Glotz, 8, 1997, p. 51-59.

J. Scheid, 1998 : J. Scheid, La religion des Romains, Paris, 1998.

J. Scheid, 1992 : J. Scheid, Myth, Cult and Reality in Ovid's Fasti, dans PCPhS, 38, 1992, p. 118-131.

J. Scheid, 1999 : J. Scheid, Epigraphie et sanctuaires guérisseurs en Gaule, dans MEFRA, 104, 1992, p. 25-40.

J. Scheid, 1999 : J. Scheid, Hiérarchie et structure dans le polythéisme romain. Façons romaines de penser l'action, dans Archiv für Religionsgeschichte, 1, 2, 1999, p. 184203.

J. Scheid, 2005 : J. Scheid, Quand faire c'est croire. Les rites sacrificiels des Romains, Paris, 2005.

R. Schilling, 1979 : R. Schilling, Ovide interprète de la religion romaine, dans Rites, cultes, dieux de Rome, Paris, 1979, p. 11-12.

R. Schilling, 1993 : Ovide, Fastes. Tome II (texte établi et traduit par R. Schilling), Paris, 1993.

H. Scholz, 1937: H. Scholz, Der Hund in der griechisch-römischen Magie und Religion, Berlin, 1937.

H. Scullard, 1981: H. Scullard, Festivals and Ceremonies of the Roman Republic, Ithaca-New York, 1981.

G. Sena Chiesa, 1981 : G. Sena Chiesa, Nuova kelebe volterrana, dans Archclass., 33, 1981, p. 203-221.

M. Sestieri Bertarelli, 1989 : M. Sestieri Bertarelli, Statuette femminili arcaiche e del primo classicismo nelle stipe votive di Poseidonia, dans RIASA, XII, 1989 5-48.

T. L. Shear, 1939 : T. L. Shear, The Campaign of 1938, dans Hesperia, 8, 1939, p. 201246.

T. L. Shear Jr, 1984 : T. L. Shear Jr, The Athenian Agora : excavations of 1980-1982, dans Hesperia, 53, 1984, p. 1-57.

E. Simon, 1997 : E. Simon, Sentiment religieux et vision de la mort chez les Etrusques dans les derniers siècles de leur histoire, dans F. Gautier, D. Briquel, (éd.), Les Etrusques. Les plus religieux des hommes. Etat de la recherche sur la religion étrusque (Actes du colloque international, Galeries nationales du Grand Palais, 1718-19 novembre 1992), Paris, 1997, p. 449-457.

R. Sorel, 2005 : R. Sorel, Hécate, dans J. Leclant (éd.), Dictionnaire de l'Antiquité, Paris, 2005, p. 1019-1020.

D. Soren, 1998 : D. Soren, Hecate and the Infant Cemetery at Poggio Gramignano, dans D.S. Soren, N. Soren (éd.), Excavations of a Roman Villa and Late Infant Cemetery near Lugnano in Teverina, Italy, Rome, 1998, p. 619-632.

D. Soren, T. Fenton, W. Birkby, 1998 : D. Soren, T. Fenton, W. Birkby, The Infant Cemetery at Poggio Gramignano : Description and Analysis, dans D. S. Soren, N. Soren (éd.), Excavations of a Roman Villa and Late Infant Cemetery near Lugnano in Teverina, Italy, Rome, 1998, p. 477-530.

C. Sorrentino, 1981: C. Sorrentino, La fauna, dans E. K. Berggren (éd.), San Giovenale, Excavations in area B, 1957-1960, dans ActaInstRomSue 4, 26 : II 4 (1981), p. 85-86. 
S. Steingräber, 1992 : S. Steingräber, Etruskische Monumental-cippi, dans Miscellanea etrusca e italica in onore di M. Pallottino, Rome, 1992 (=ArchClass, 43, 1991 [1992]), p. 1079-1102.

S. Steingräber, 1997 : S. Steingräber, Le culte des morts et les monuments de pierre des nécropoles étrusques, dans F. Gautier, D. Briquel, (éd.), Les Etrusques. Les plus religieux des hommes. État de la recherche sur la religion étrusque (Actes du colloque international, Galeries nationales du Grand Palais, 17-18-19 novembre 1992), Paris, 1997, p. 97-116.

Storia del Mezzogiorno, 1991 : Storia del Mezzogiorno, I, 1, Il Mezzogiorno antico, Naples, 1991, p. 237-300.

S. Sublimi Saponetti, 1991: S. Sublimi Saponetti, Appendice, I resti animali di Gravetta (Lavello PZ), dans M. Tagliente, M. P. Fresa, A. Bottini, Relazione sull'area daunio-lucana e sul santuario di Lavello, dans Comunità indigene e problemi della romanizzazione nell'Italia centro-meridionale, IV-III sec. a. C., Actes du colloque international, Rome 1990, Rome, 1991, p. 105-108.

E. Tabeling, 1932: E. Tabeling, Mater Larum. Zum Wesen der Larensreligion, Frankfurter Studien zur Religion und Kultur der Antike, I, 1932.

A. Tagliacozzo, 1989: A. Tagliacozzo, Annali dei resti faunistici dell'area sacra di S. Omobono, dans Il viver quotidiano in Roma arcaica. Materiali degli scavi del Tempio Arcaico nell'area sacra di S. Omobono, Roma, 1989, p. 65-69.

M. Tagliente, M. P. Fresa, A. Bottini, 1991 : M. Tagliente, M. P. Fresa, A. Bottini, Relazione sull'area daunio-lucana e sul santuario di Lavello, dans Comunità indigene e problemi della romanizzazione nell'Italia centro-meridionale, IV-III sec. a. C., Actes du colloque international, Rome 1990, Rome, 1991, p. 93-104.

Thesaurus: Thesaurus cultus et rituum antiquorum (ThesCRA). I. Processions. Sacrifices. - Libations. - Fumigations. - Dedications, [éd. par le J. Paul Getty Museum et la Fondation pour le Lexicon Iconographicum Mythologiae Classicae, LIMC].- Los Angeles : The J. Paul Getty Museum, 2004.

M. Torelli, 2000 : M. Torelli, La religione etrusca, dans Gli Etruschi, Milan, 2000, p. $273-$ 289.

J. M. C. Toynbee, 1973 : J. M. C. Toynbee, Animals in Roman Life and Art, Londres, 1973.

A. D. Trendall, 1987 : A. D. Trendall, The Red-Figured Vases of Paestum, Rome, 1987.

N. Turchi, 1939 : N. Turchi, La Religione di Roma antica, Bologne, 1939.

J. Untermann, 2000 : J. Untermann, Wörterbuch des Oskisch-Umbrischen, Heidelberg, 2000.

W. van Andringa, S. Lepetz, 2003 : W. van Andringa, S. Lepetz, Le ossa animali nei santuari: per un'archeologia del sacrificio, dans O. de Cazanove, J. Scheid (éd.), Sanctuaires et Sources dans l'Antiquité, Naples, 2003, p. 85-96.

L. B. van der Meer, 1987 : L. B. van der Meer, The Bronze Liver of Piacenza. Analysis of a Polytheistic Structure, Amsterdam, 1987.

J.-P. Vernant, Hestia-Hermès. Sur l'expression religieuse de l'espace et du mouvement chez les Grecs, dans Mythe et pensée chez les Grecs, Paris, 1965, p. 157-201.

E. Vetter, 1953 : E. Vetter, Handbuch der italischen Dialekte. Band I, Heidelberg, 1953.

P. Veyne, 1976 : P. Veyne, L'Inventaire des différences, Paris, 1976.

P. Vidal-Naquet, 1991 : P. Vidal-Naquet, Le chasseur noir, Paris, 1991.

W. Warde Fowler, 1925 : W. Warde Fowler, The Roman Festivals of the Period of the Republic, Londres, 1925.

G. Wissowa, 1912 : G. Wissowa, Religion und Kultus der Römer, Munich, 1912. 
G. Wissowa, Römische Sagen, dans Gesammelte Abhandlungen, Munich, 1904, p. 129143.

N. J. Zagarianis, 1975 : N. J. Zagarianis, Sacrifices de chiens dans l'Antiquité classique, dans Platon, 1975, 27, p. 322-329.

N. J. Zagarianis, 1980-1981: N. J. Zagarianis, Le chien dans la mythologie et la littérature gréco-latines, dans Platon, 32-33, 1980-1981, p. 32-33, 52-87.

P. Zancani Montuoro, 1937 : P. Zancani Montuoro, Heraion alla foce del Sele, dans Notizie degli Scavi 13, 1937, p. 299-301.

P. Zancani Montuoro, U. Zanotti Bianco, 1951 : P. Zancani Montuoro, Heraion alla foce del Sele. I. Il santuario, il tempio della dea, rilievi figurati varii, Rome, 1951. 